UNIVERSIDAD NACIONAL DE LA PLATA

FACULTAD DE HUMANIDADES Y CIENCIAS DE LA EDUCACIÓN

MAESTRÍA EN LINGÜÍSTICA DISCURSIVA

\title{
LA CONSTRUCCIÓN INTERACTIVA DE LA IDENTIDAD EN LA ENTREVISTA PERIODÍSTICA DE HUMOR: CATEGORÍAS, EJECUCIÓN Y MARCOS.
}

Marcela R. Morales

Director:

Dra. Guiomar Ciapuscio

AÑO 2005 
Para Ana, un pequeño tributo a su optimismo y alegría de vivir. 


\section{AGRADECIMIENTOS}

Al promediar este trabajo, encuentro más que acertada la visión de Antos acerca del proceso de producción textual como "resolución de problemas". La tarea de redactar esta tesis representó para mí un desafío en múltiples dimensiones, que no hubiera podido llevar a cabo sin el apoyo de diferentes personas, quienes en mayor o menor medida contribuyeron a que cumpliera mi objetivo.

En primer lugar quiero agradecer especialmente a mi directora de tesis, Dra. Guiomar Ciapuscio, por la paciencia, claridad y sensatez con que guió mis pasos desde las charlas preliminares, en las cuales se gestó el proyecto, hasta la redacción de la versión final de este trabajo. Quiero destacar particularmente su calidez humana, su solidez profesional y la generosidad con que dispuso de su tiempo en toda ocasión, que hicieron mi tarea mucho más placentera y sencilla. Sin su guía y respaldo permanente no me hubiera sido posible recorrer el camino, no exento de obstáculos, hacia la meta.

También quiero agradecer a la Dra. Luisa Granato, quien ha sido el motor de la Maestría en Lingüística de la U.N.L.P y sin cuyo impulso no hubiera sido posible llegar a esta etapa final. Particularmente quiero agradecerle el haber abierto su biblioteca personal en forma generosa y desinteresada en toda ocasión.

A Laura Spoturno y familia, quienes me proporcionaron la mayor parte del corpus, va también mi agradecimiento, ya que me permitieron ahorrar tiempo precioso.

A mi esposo y a mis hijos, quiero agradecerles el haber sobrellevado con paciencia las ausencias durante los años de cursada de la Maestría y los altibajos en mi humor durante la redacción de la tesis. Muy especialmente agradezco a mi padre, quien ha apoyado siempre mis esfuerzos intelectuales y 
que, diccionario en mano, estuvo siempre listo para resolver mis dudas mientras redactaba la tesis.

A María Luisa, Cristina y Agustín agradezco el apoyo logístico en las etapas finales de redacción. 


\section{ÍNDICE}

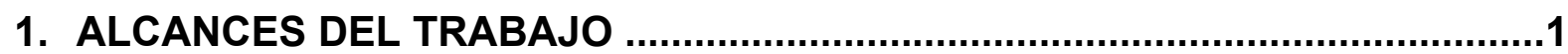

1.1 Objetivos generales y específicos ………....................................................

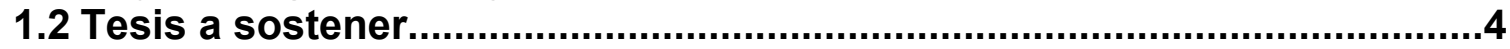

1.3 Macroestructura del presente trabajo ....................................................



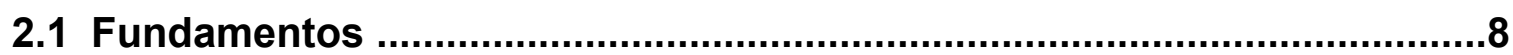

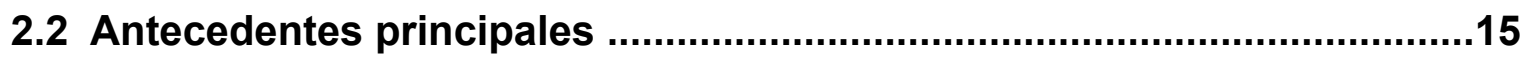

2.2.1 Sobre la identidad en el habla ................................................15

2.2.2 Sobre la alternancia de marcos ..................................................18

2.2.3 Sobre la hipérbole y la ironía ........................................................ 19

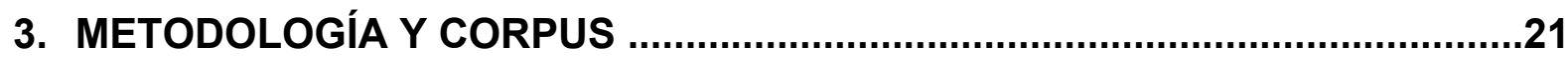

B. SECCION ANALÍTICA ..........................................................27

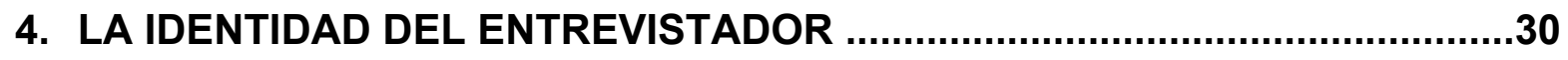

4.1 Alternancia de marcos ...................................................................... 30

4.2 Figuras retóricas, estrategias discursivas generales y recursos

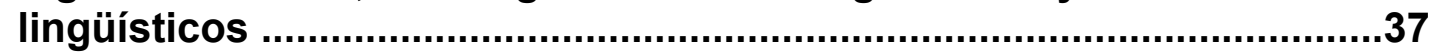

4.2.1 Figuras retóricas clásicas .........................................................38

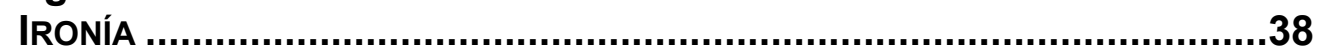

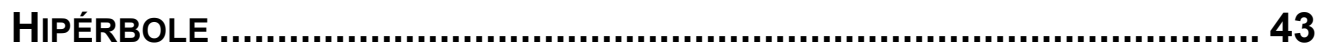

4.2.2 Estrategias discursivas generales ...............................................46

EXPRESIÓN DE UNA OPINIÓN POR EL OTRO ..........................................46

ESCENIFICACIONES Y EMPLEO DE OTRAS VOCES .................................47

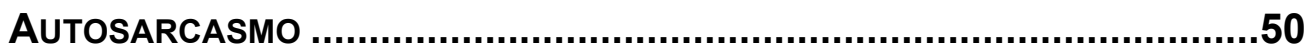

REFORMULACIONES Y EXPANSIONES DE LOS DICHOS DEL OTRO ................51

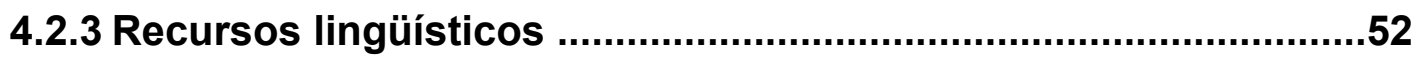

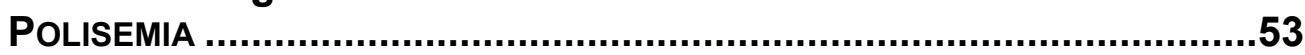

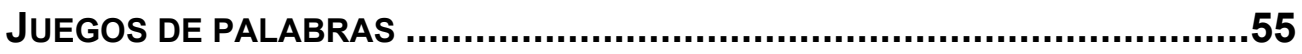

EMPLEO DE COLOQUIALISMOS, VULGARISMOS Y VOCES LUNFARDAS ....... 56 


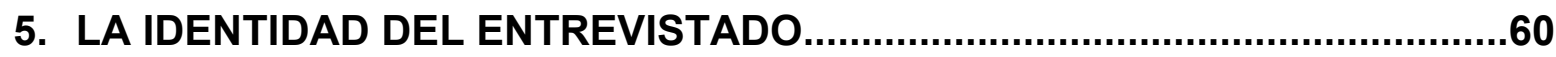

Procesos interactivos de categorización ..................................................60

5.1 Categorizaciones directas e indirectas ............................................61

5.2 Figuras estereotípicas ……....................................................................63

5.3 Rasgos estereotipados ...........................................................................65

5.4 Actividades ligadas a la categoría ........................................................66

6. LA IDENTIDAD DE LOS INTERLOCUTORES …........................................70

6.1 Fórmulas de tratamiento ....................................................................... 70

6.2 Alternancia de marcos y fórmulas de tratamiento ............................... .75

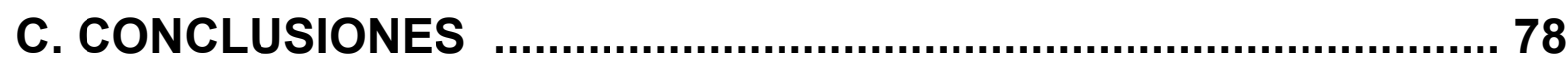

BIBLIOGRAFÍA

APÉNDICE (corpus y tablas) 


\section{A. INTRODUCCIÓN}

\section{ALCANCES DEL TRABAJO}

La identidad de una persona, según la visión cognitivista de Van Dijk (2000:152 y ss.) es una representación mental que puede ser la suma de varias identidades sociales. En su autorrepresentación las personas se construyen a sí mismas como miembros de varias categorías y grupos. Este esquema está ubicado en la memoria episódica personal y es una abstracción construida desde las experiencias personales de los acontecimientos. Por otro lado, existen las prácticas situadas reales de los actores sociales que pueden ser consideradas como manifestaciones de algunos aspectos de la identidad personal.

Al interactuar en la vida cotidiana, las personas se muestran de cierta manera ante los otros. A través de su vestimenta, su lenguaje corporal y su lenguaje verbal revelan en forma consciente o inconsciente su identidad, partes de ella, o de otra identidad con la que desean mostrarse ante los demás.

Sin embargo, la noción de identidad de la que hemos partido en este trabajo no tiene que ver con aquella identidad conformada por un conjunto fijo de propiedades y operaciones que pertenecen al estrato cognitivo de los individuos y que se evidencia, por ejemplo, en lo que dicen o hacen al entrar en contacto con otros miembros de la sociedad. La perspectiva es distinta: se intenta mostrar cómo la identidad es el resultado de un proceso discursivo de elaboración conjunta del cual son responsables los participantes del evento de habla, y cómo esa identidad es relevante local y temporalmente en su contexto de uso. La identidad es empleada por los participantes como un recurso para establecer a través del habla cómo deben ser vistos y oídos por los demás (Antaki \& Widdicombe, 1998). 
En este trabajo nos interesa focalizar sobre el proceso de coconstrucción de identidades discursivas ${ }^{1}$, es decir aquellas que son desplegadas por los participantes en el fluir de la interacción (en nuestro caso la entrevista periodística de humor) con un propósito particular, que depende del fin que la interacción posea para los participantes involucrados; en este caso, el entrevistador y el entrevistado desean presentarse de cierta manera ante la audiencia lectora.

Las entrevistas periodísticas de humor que componen el corpus de nuestro trabajo constituyen un escenario apropiado para la puesta en escena de los personajes de Entrevistador y Entrevistado (Arfuch, 1995:55), quienes se apoyan mutuamente para llevar adelante la interacción y construyen colaborativamente las identidades de ambos: la del entrevistador, que presenta rasgos de uno de los estereotipos del argentino: el "vivo", gracioso, ingenioso, irónico, y la del entrevistado, que varía según quién ocupe ese rol. El público lector constituye el tercero silencioso hacia quién se orienta el discurso y para quién, en última instancia, se recrean las identidades de entrevistador y entrevistado.

La principal corriente que constituye la línea conductora de este trabajo es la perspectiva etnometodológica de H. Sacks y sus seguidores. Apoyándose en investigaciones que se han hecho en el pasado y en otras más recientes, este trabajo ha buscado combinar la metodología del Análisis de Dispositivos de Categorización o Membership Categorization Analysis (de ahora en más MCA) (Sacks, 1992) la teoría de la ejecución o verbal art performance de R. Bauman (1977) y el concepto de marcos (frames) de interpretación (Goffman, 1974), (Tannen, 1993). Estas líneas de investigación en conjunto nos

\footnotetext{
${ }^{1}$ El término significa aquí en forma general "identidades que los participantes despliegan en el discurso"; no está usado en el sentido de Zimmerman (1998: 90-91), quien llama identidades discursivas a aquellas identidades ligadas a una determinada actividad durante la interacción y que pueden variar de turno a turno, por ejemplo, interrogador, respondedor, oyente, narrador de anécdota, etc.
} 
permitirán explicar claramente los fenómenos observados en el corpus bajo análisis.

Cabe agregar que la línea del MCA ha sido la de menor difusión dentro de la Etnometodología, a pesar de que Harvey Sacks dedicó varias de sus conferencias al estudio de las categorías. Numerosos etnometodólogos se interesaron por el análisis de las secuencias en el habla (cf. Schenkein, 1978), que si bien no es incompatible con el MCA (Fitzgerald \& Housley, 2002), representa una línea distinta de investigación. Nos interesa explorar el terreno que ha sido menos trabajado dentro de la Etnometodología y adoptar sus métodos de análisis porque creemos que, en líneas generales, estos se ajustan al corpus que estudiamos.

No se han encontrado dentro de la bibliografía consultada artículos o estudios realizados sobre textos escritos, ya que la Etnometodología se interesa principalmente en el habla en la interacción. Creemos poder mostrar, sin embargo, que los métodos de investigación utilizados por la Etnometodología pueden utilizarse en gran medida para esclarecer los fenómenos observables en textos que fueron inicialmente orales pero que luego fueron transcriptos y recontextualizados para su publicación.

\subsection{Objetivos generales y específicos}

El objetivo general de este trabajo es contribuir al entendimiento de cómo las personas construyen interactivamente distintas identidades para sí mismos y para los demás en situaciones de habla concretas en las que se ven inmersos al interactuar con otros miembros de la sociedad.

Distintos recursos permiten a los participantes construir sus identidades en el fluir de la interacción. El objetivo específico de este trabajo es mostrar parte del repertorio de recursos discursivos, retóricos y lingüísticos por medio de los cuales los hablantes llevan a cabo su trabajo discursivo identitario y 
cómo estos recursos hacen posible que las identidades de entrevistador y entrevistado estén disponibles para la audiencia en la entrevista escrita.

No se ha pretendido hacer un análisis cuantitativo sino más bien un relevamiento de los principales recursos discursivos, retóricos y lingüísticos empleados por los hablantes en el contexto de la entrevista. Es muy posible que los recursos analizados en esta investigación sean comunes a otros tipos de discurso y que algunos de ellos resulten ser prototípicos de la manera en que las personas construyen su identidad en el habla. Para poder fundamentar esto último serán necesarias futuras investigaciones.

\subsection{Tesis a sostener}

A partir de la lectura de los textos teóricos y el examen cuidadoso del corpus podemos formular un conjunto de tesis ${ }^{2}$, que luego serán puestas a prueba en el análisis.

Las tesis de las que partimos son:

a) La identidad del entrevistador se construye principalmente a través de su condición de ejecutante o performer (Bauman, 1977).

b) La identidad del entrevistador se construye, además, a través de un recurso recurrente: la alternancia estratégica de marcos (el marco "serio" y el marco "humorístico") o "frame shifting" (Tannen \& Wallat, 1993:65).

c) Parecería haber una cierta correlación entre el grado de familiaridad o distancia entre los participantes y la frecuencia con que se presenta la alternancia de marcos. Las fórmulas de tratamiento pronominal que habitualmente señalan mayor o menor distancia en principio podrían ser indicadores de ello.

\footnotetext{
${ }^{2}$ Hablamos de "tesis" y no de "hipótesis" en concordancia con el marco teórico en el que trabajamos. (ver p.9 de este trabajo).
} 
d) La identidad del entrevistado se construye fundamentalmente a partir de procesos de auto y heterocategorización (Kesselheim, 1998). Estos procesos pueden presentarse con diferentes grados de negociación, disputa o resistencia (Day, 1998).

Sostenemos que la identidad del entrevistador se construye principalmente a través de su condición de ejecutante, siguiendo los lineamientos de Bauman (1977), según los cuales el performer utiliza un estilo de habla (speech style) particular que transforma el uso corriente del lenguaje en un lenguaje con características propias y que es puesto en función para entretener a la audiencia.

Además, el entrevistador se apoya en el cambio de marcos (Tannen, 1993) para su trabajo identitario, alternando entre el marco "serio" y el marco "humorístico". El entrevistador entra y sale de uno y otro marco en un juego retórico-lingüístico constante que le permite, junto con su rol de ejecutante, crear y proyectar una determinada imagen de sí mismo para el público lector y para su interlocutor del momento. El entrevistado, en la mayoría de los casos, acompaña al entrevistador en su juego discursivo con risas o comentarios alusivos, ayudando a la construcción del marco humorístico, y contribuyendo de esa manera a la creación conjunta del discurso y a la constitución de la identidad del entrevistador.

La alternancia de marcos parece darse más frecuentemente cuando existe una mayor cercanía entre el entrevistado y el entrevistador en la entrevista. Un mayor grado de familiaridad preexistente entre el entrevistado y el entrevistador seguramente permite predecir que existirá mayor cercanía durante la entrevista misma, y tiene además influencia sobre la posibilidad por parte del entrevistador de hacer bromas. Podemos conjeturar que, en esos casos, el número de marcos "humorísticos" que se construya será mayor. Sin embargo, y siguiendo los lineamientos de la Etnometodología, nos interesa considerar solamente aquello que es manifestado durante la interacción y ver sus consecuencias sobre el fluir del discurso; no tendremos en cuenta, por lo 
tanto, aquello que podría corresponder a una situación preexistente a la interacción.

En primera instancia, la distancia en la interacción se refleja, entre otras cosas, en la elección de distintas fórmulas de tratamiento utilizadas por los participantes para dirigirse al otro (Carricaburo, 1997:9). El uso de fórmulas de respeto o familiaridad podría estar, en principio, en relación con el tipo de marcos que se crean en el diálogo: a mayor distancia entre los participantes, menor número de marcos de humor y a menor distancia, mayor frecuencia de marcos humorísticos

Por otro lado, la identidad del entrevistado se construye a partir de procesos de categorización interactivos en los que se autoincluye o es incluido por el entrevistador. El entrevistador es quien maneja los tópicos y por ende, el curso de la interacción, y también es quien puede inscribir al entrevistado en determinada categoría a través de sus preguntas. El entrevistado, a través de sus respuestas, puede a) ratificar su pertenencia a una cierta categoría, b) resistirse a ser incluido o c) autoinscribirse en una determinada categoría.

En resumen, la idea fundamental del presente trabajo es echar luz sobre los principales recursos discursivos, retóricos y lingüísticos empleados por los participantes de la interacción para constituir una determinada identidad en su accionar discursivo.

\subsection{Macroestructura del presente trabajo}

El presente trabajo está dividido en tres macro secciones: INTRODUCCIÓN, SECCIÓN ANALÍTICA y CONCLUSIONES. La primera está constituida por los capítulos 1, 2 y 3 . En el capítulo 1 se plantean los alcances del trabajo, los objetivos generales y específicos, y las tesis a sostener. El capítulo 2 presenta el marco teórico (los fundamentos y los antecedentes principales), mientras que el capítulo 3 está dedicado a la metodología y a la caracterización del corpus. La Sección Analítica comprende los capítulos 4 y 5 , 
en los cuales se analiza la construcción de la identidad del entrevistador y la del entrevistado respectivamente, y el capítulo 6 , en el cual se muestra la incidencia de las fórmulas pronominales de tratamiento en la construcción de la identidad de los interlocutores. Finalmente, en la sección Conclusiones, se detallan los resultados y se ofrecen algunas consideraciones finales.

En el Apéndice se incluyen las 40 entrevistas que conforman el corpus, numeradas del I al XL. Los pares adyacentes (pregunta / respuesta) están identificados con números arábigos (uno por cada par). A continuación del corpus, se encuentran las tablas que se diseñaron para sistematizar los datos (Tablas I, II y III). 


\section{MARCO TEÓRICO}

\subsection{Fundamentos}

Como ya se ha indicado, este trabajo enfoca sobre el proceso dinámico de co-construcción de identidades discursivas en la entrevista periodística de humor, considerando al habla como un modo de acción (Austin, 1996; Arfuch, 1995:46). La identidad discursiva es aquella que emerge en el discurso mismo y que es construida por los participantes de la interacción durante el transcurso del evento de habla. Los participantes construyen para sí mismos una identidad con la que desean presentarse ante el otro. Sin embargo, sostenemos que esas identidades discursivas son construidas en forma interactiva; es decir, que ambos participantes contribuyen a moldear la identidad del otro a través de su accionar discursivo y a su vez cada uno de ellos orienta su propia identidad hacia la del otro. En consecuencia, la identidad de cada participante es configurada en forma conjunta (Fitzgerald \& Housley, 2002; Mc Ilvenny, 1996).

La entrevista periodística presenta un patrón sumamente interesante, ya que existe un tercer participante presupuesto y silencioso pero no menos importante: la audiencia. Y justamente es en función de los miembros de la audiencia que la entrevista se desarrolla como práctica social. Aunque no se los nombra directamente, los potenciales lectores u oyentes de la entrevista constituyen una presencia latente y relevante en el discurso, ya que hacia ellos está orientada la interacción y serán ellos quienes reconstruyan las identidades de entrevistador y entrevistado (Arfuch, 1995:36).

La noción de texto que tendremos en cuenta, por ser la que más adecuadamente se ajusta a nuestros propósitos, es la de E. Gülich (1986) ${ }^{3}$, quien sigue una línea dentro de la lingüística textual influida por el análisis conversacional etnometodológico, para la cual el texto es una actividad lingüística compleja que se realiza por medio de una tarea interactiva de los

\footnotetext{
${ }^{3}$ Citado en Ciapuscio (1994:56)
} 
participantes de la comunicación, e independientemente de si tiene lugar un cambio de hablante.

A continuación haremos mención de las corrientes que constituyen el basamento teórico del presente trabajo y estableceremos su asociación con el corpus que se analizó.

Abordamos el análisis del corpus desde una perspectiva etnometodológica. La Etnometodología ha indagado básicamente en la naturaleza de la interacción hablada, como medio para explicar el orden social. Como ya se mencionó anteriormente, creemos que su línea de investigación se ajusta al fenómeno que queremos analizar, ya que la entrevista es primariamente un género oral. En nuestro caso, la entrevista ha sido transcripta y por lo tanto recontextualizada; sin embargo, los fenómenos que nos ocupan son todavía observables aun cuando la entrevista ha sido despojada de casi todas las marcas de oralidad (Arfuch, 1995:35).

La Etnometodologïa tiene como uno de sus rasgos distintivos la insistencia en trabajar sobre los materiales en estudio para lograr descubrir en ellos distintos aspectos explicativos de la lengua en uso, en vez de seleccionar problemas y datos con respecto a un determinado marco teórico que propicie el análisis a partir de categorías prefijadas. Esto es coherente con el interés principal de la Etnometodología: el orden social como el logro (achievement) de los miembros de una comunidad, concebidos estos como actores sociales que investigan el mundo a su alrededor, utilizando el lenguaje para llevar a cabo las tareas y asuntos en los que se ven inmersos en su accionar diario (Hester \& Eglin, 1997:1 y ss.).

En la perspectiva etnometodológica la vida social de las personas es vista como aquello que las personas hacen en forma conjunta y que se manifiesta en sus prácticas diarias. La identidad es constituida y empleada en el habla como parte de las rutinas cotidianas. Según esta visión, la identidad de una persona está conformada por la manera en que se muestra, se inscribe en 
alguna categoría o se excluye de ella. Las personas no poseen identidades fijas que provocan en otros sentimientos y acciones, sino que se orientan hacia una determinada identidad, en el aquí y ahora de la interacción, como un fin en sí mismo o para algún otro propósito (Antaki \& Widdicombe, 1998:2a).

Nuestro trabajo se basa, por un lado, en la línea de análisis que se desprende de las investigaciones de Harvey Sacks (1992) llamada MCA (Membership Categorization Analysis) y que se escindió del Análisis Conversacional. EI MCA exhibe un desarrollo menor -especialmente en contribuciones empíricas- que el Análisis Conversacional, por eso creemos que constituye una línea de investigación en la cual todavía existen áreas sin explorar, y que, además, proporciona herramientas interesantes para explicar ciertos fenómenos del discurso tal como el que nos ocupa.

Según Antaki y Widdicombe (1998:3a) los siguientes puntos son centrales para analizar la identidad en el habla:

a) Decir que una persona tiene una cierta identidad (ya sea la persona que habla, a la que se le habla o de la que se habla) es incluirlo en una categoría con ciertas características.

b) La inclusión se hace en el aquí y ahora de la interacción. Las categorías son expresiones deícticas.

c) La identidad es relevante a la interacción en curso. La identidad que interesa es la que tiene un efecto visible en el desarrollo de la interacción. Si una determinada identidad no es desplegada en la interacción, entonces dicha identidad no es relevante ni tiene consecuencias para esa interacción.

d) El valor de poseer una identidad radica en las consecuencias que esta trae a la interacción. 
e) Todo esto es visible en la forma en que las personas explotan las estructuras de la conversación. ${ }^{4}$

Las categorías (Sacks, 1992) a las que alude el título de este trabajo son recursos o herramientas ${ }^{5}$ que permiten a los hablantes hacer descripciones y explicaciones de sí mismos o de otras personas presentes o no en la interacción. Las categorías forman colecciones, por ejemplo, las categorías "hijo" y "madre" forman parte de la colección o dispositivo (en inglés "device") "familia". Los hablantes se inscriben a sí mismos o inscriben a otros en diferentes categorías que son relevantes para la interacción en curso según sus propósitos comunicativos particulares.

Durante la interacción los participantes con frecuencia se presentan a sí mismos o a otras personas como miembros de una o varias categorías. Definen su pertenencia o no a estas categorías creando una determinada representación de sí mismos o de otros, aquella que es relevante en el momento de la interacción. Utilizan distintos recursos lingüísticos para llevar a cabo el proceso de categorización, por ejemplo, nombrar directamente (soy / es un $X$ ), aludir a actividades ligadas a la categoría (yo hago $X$ / él hace $X$ ) o asignar atributos de la categoría (tengo $X$; soy $X /$ tiene $X /$ es $X$ ), o en forma más sutil por medio de un trabajo discursivo indirecto nombrando en su descripción otra persona o cosa (Day, 1998). Estas categorías permiten a los interlocutores hacer numerosas inferencias sobre la persona o personas a las que se hace alusión.

En las entrevistas analizadas existen numerosas instancias en las que el entrevistador, a través de sus preguntas, incluye al entrevistado en alguna categoría, por ejemplo, "Gato, ¿sos un aristócrata venido a menos?" [XIV 1] . En otros casos el entrevistador invita al entrevistado a hablar de sí mismo: “Solita, ¿vos quién sos?”. Esto generalmente fuerza al entrevistado a incluirse en una cierta categoría : "Soy una laburanta" [I 1]

\footnotetext{
${ }^{4}$ Traducción de la autora

${ }^{5}$ Para delimitación de este concepto cf. Hester y Eglin, 1997:20.
} 
La Etnometodología se interesa en el carácter situado de las categorías; es decir, tal como estas son utilizadas por los participantes en el momento mismo de la interacción. Todas las categorías son situadas, en el sentido de que su significado depende de lo que quieren decir para la persona que las utiliza por esta única vez en un determinado contexto.

La actividad de categorización es innata y universal. Cumple la función de ordenar la experiencia y ayudar en la interpretación y aprehensión de los fenómenos de la vida. Las categorías se asemejan a los estereotipos, pero mientras estos son un fenómeno cognitivo estático, las categorizaciones son un fenómeno dinámico que se produce durante el accionar discursivo (cf. Ciapuscio y Kesselheim, 1997:113 nota al pie). Hester y Eglin (1997:20) sugieren que cuando se habla de categorías debemos pensar que estas son constituidas en el uso, más que imaginar que son maquinarias preexistentes que están a disposición de los hablantes.

El término "ejecución", al que se hace referencia en el título de este trabajo, es la traducción de performance (Bauman, 1977). El término performance transmite en inglés un sentido dual de acción artística y de evento artístico. A su vez este término concuerda con el significado convencional de performance ("desempeño") y sirvió a la Antropología Lingüística para la reorientación del folklore como contenido material hacia el folklore como comunicación. El arte verbal como ejecución (verbal art as performance) es, según Bauman, un modo de hablar creativo, logrado. Nos interesa considerar este concepto en su sentido más amplio, tal como lo explicita Bauman: "El arte verbal puede comprender tanto la narración mítica como el habla que se espera de las emisiones de ciertos miembros de la sociedad y es la ejecución la que los aúna de modos variables y culturalmente específicos...." 6 (Bauman, 2001:26-27).

\footnotetext{
${ }^{6}$ El énfasis es nuestro
} 
El performer o ejecutante se erige como tal frente a la audiencia que lo autoriza. La ejecución representa una transformación de los usos referenciales básicos "serios" o "normales" del lenguaje. Durante una ejecución emergen señales en el intercambio comunicativo entre el ejecutante y su audiencia que le transmiten al oyente la idea de que debe interpretar lo que se dice en un sentido especial no literal.

La performance o ejecución, que está relacionada con la función poética, constituye un principio organizador del discurso y sirve a la vez como marco de interpretación (Bauman, 2001:28). Los recursos que el ejecutante utiliza para la puesta en clave de una performance son: el uso de códigos o formas especiales, tropos del lenguaje, recursos estilísticos formales, pautas prosódicas especiales, y cambios de código. (Bauman, 2001:33). Todos estos recursos adquieren una significación especial al estar enmarcados dentro de una performance.

La teoría de la performance, tal como fuera formulada por R. Bauman (1977), nos permite explicar la construcción de la identidad del entrevistador a través de su posicionamiento como performer o ejecutante autorizado frente al entrevistado y a la audiencia (lectora en este caso) que juzgará su habilidad discursiva y su potencial como entrevistador en forma diferida y disfrutará de la experiencia. En cada entrevista el entrevistador pone en escena un personaje y lo hace actuar según un patrón conocido por la audiencia y por los entrevistados. La identidad discursiva del entrevistador reemerge en cada performance y es desplegada ante el interlocutor y posteriormente ante la audiencia lectora.

La noción de marcos (frames) fue formulada inicialmente por Bateson (1972), y posteriormente desarrollada por Goffman (1974) y luego por Tannen y otros (1993). El marco es la percepción que tienen los hablantes acerca de lo que está ocurriendo en la interacción y es el que indica a los participantes el sentido en que debe interpretarse lo que dicen. El sentido de una emisión no se logra con el contenido de las palabras mismas, sino a través de un 
metamensaje o de las actitudes de los hablantes hacia el otro y hacia la conversación en la que están involucrados. En las entrevistas que analizamos pueden identificarse numerosos marcos "serios", en los cuales se habla de diferentes tópicos; alternando con estos suele presentarse una emisión o una secuencia de emisiones que pueden ser consideradas como marcos "humorísticos". Aunque a veces lo que el entrevistador (o el entrevistado) dice puede resultar agresivo y hasta hostil, sus palabras están enmarcadas por un metamensaje que señala: "Esto es broma" (cf. Bateson, 1972).

En nuestro caso, la alternancia de marcos (cf. "frame shifting", Tannen \& Wallat, 1993:65) es utilizada por uno de los participantes como uno de los recursos estratégicos para construir su identidad. El entrevistador alterna el marco serio con el marco humorístico como recurso característico de su performance. Esto le permite construir su identidad como gracioso, ingenioso y transgresor. En nuestro corpus puede observarse que la alternancia de marcos tiene distinta frecuencia, problema que estudiamos en la sección analítica.

Como ya se ha mencionado, los hablantes utilizan distintos recursos para construir su identidad. En nuestro caso, el entrevistador recurre a un uso especial del lenguaje, marcado por recursos estilísticos particulares que contribuyen a crear el efecto humorístico dentro de los que llamamos "marcos humorísticos" y que a su vez, dan la clave de la performance. Los recursos que surgen como relevantes son, por un lado, figuras estilísticas clásicos como la hipérbole y la ironía, y por otro, diversas estrategias discursivas como expresar una opinión por el otro, crear escenarios y emplear otras voces, reírse de sí mismo (autosarcasmo), reformular y expandir de manera interesada y/o humorística intervenciones del interlocutor. Asimismo, el empleo de ciertos términos del habla coloquial y del lunfardo por parte del entrevistador contribuye a crear el efecto humorístico. El criterio de selección de los recursos empleados fue producto de una lectura cuidadosa de los textos que nos permitió identificar las estrategias y recursos que son utilizados con regularidad por el entrevistador en las diferentes entrevistas. 


\subsection{Antecedentes principales}

En esta sección presentamos sucintamente los principales trabajos que han sido de utilidad para nuestro análisis.

\subsubsection{Sobre la identidad en el habla}

En comparación con el Análisis Conversacional, la línea de investigación del MCA o Membership Categorization Analysis ha tenido escasa difusión. Algunos autores que han trabajado en la perspectiva del MCA son: Mc Ilvenny (1996), Hester y Eglin (1997), Kesselheim y Ciapuscio (1997), Kesselheim (1998), Antaki y Widdicombe (1998), Matoesian (1999), y más recientemente Fitzgerald y Housley (2002), Ciapuscio (2003) y Gülich (2003). Estos autores han examinado la forma en que las personas construyen su identidad en el discurso por medio de las categorizaciones.

En el artículo de Mc Ilveny (1996) se estudia cómo las identidades culturales son negociadas en un debate público entre el orador y la audiencia, en el cual los oradores logran la construcción de la afiliación de grupo, la respuesta de la audiencia y la argumentación en el habla. A diferencia de nuestro caso, la audiencia está presente y es parte de la interacción misma.

Hester y Eglin (1997) introducen los conceptos y métodos del MCA establecidos por Sacks y reseñan los principales estudios dentro del área. Distinguen el carácter etnometodológico del MCA de otras formas relacionadas de investigación que se encuentran fuera de la Etnometodología como la Antropología Lingüística y la Antropología Cognitiva. Dentro de esta obra destacamos el tercer capítulo, en el cual R. Watson discute las relaciones entre MCA y el análisis secuencial de la conversación, que es considerada como un área de investigación independiente.

Kesselheim y Ciapuscio (1997) analizan consultas realizadas por inmigrantes en la Dirección de Migraciones en Argentina para lograr su 
radicación, desde una perspectiva lingüístico conversacional. Se interesan en la construcción del contexto en la interacción a través de la identidad y la relación de los interlocutores. Los autores muestran que, a diferencia de lo que ocurre en situaciones informales, el marco institucional bloquea las inferencias ligadas a atributos, propiedades o actividades de las categorías nacionales que son el objeto de estudio. Muestran que, en ocasiones, cuando los interlocutores crean contextos humorísticos y suspenden el contexto institucional, se desatan las actividades de categorización. Kesselheim (1998) analiza el discurso migratorio en la Argentina y se concentra en la autorrepresentación de los interactuantes y el proceso interactivo de construcción de la identidad étnica grupal. Más recientemente, en su tesis doctoral ${ }^{7}$, Kesselheim presenta un estudio comprehensivo sobre la constitución conversacional de grupos, en el discurso argentino actual sobre la inmigración.

Antaki y Widdicombe (1998) presentan una colección de trabajos de diferentes autores, quienes adhieren a la perspectiva etnometodológica de Sacks y analizan la identidad tal como es usada en el habla, teniendo en cuenta su relevancia local y temporal en la interacción en curso. Mencionamos sólo los más salientes. En primer lugar, Antaki y Widdicombe (1998a) quienes presentan los lineamientos generales del tema. Edwards (1998) observa el surgimiento de diferentes categorías en charlas entre una pareja y su consejero matrimonial y presta especial atención al uso contrastivo de las categorías girl y woman. Widdicombe (1998) analiza entrevistas informales en las que los hablantes aceptan o rechazan su categorización como "punks" o "góticos". Antaki (1998) muestra cómo la categoría "Fagin" es utilizada en forma humorística. Sugiere que esta categoría no necesariamente refiere a un componente cultural, sino que debe ser vista como una identidad invocada por los participantes en la interacción, que es relevante en su contexto de uso y

\footnotetext{
${ }^{7}$ Prozesse der Gruppenkonstitution: Die konversationelle Herstellung von Gruppen im aktuellen argentinischen Einwanderungsdiskurs [Procesos de constitución de grupos: la constitución conversacional de grupos en el discurso argentino actual sobre la inmigración] Universidad de Bielefeld, 2003.

8 "Fagin" es un personaje de la novela Oliver Twist de Dickens, que lidera una banda de niños ladrones y viste harapos. En el artículo en cuestión una persona caracteriza a otra como Fagin al ver sus guantes recortados, que exhiben sus dedos.
} 
que realiza un cierto trabajo discursivo para los hablantes. Day (1998) analiza la identidad étnica como un recurso de los hablantes que puede ser utilizado para descalificar al otro. En estos casos la persona aludida puede usar ciertos procedimientos para resistirse, tales como "minimizar la diferencia" o "etnificar al etnificador."

Matoesian (1999) analiza cómo la identidad de experto emerge en la interacción discursiva entre el fiscal y el médico (quien es a su vez el acusado) durante el interrogatorio de un resonado juicio. Utilizando la noción de footing (posicionamiento) de Goffman, Matoesian analiza cómo el fiscal y el acusado hacen uso del estilo directo e indirecto, del paralelismo repetitivo y de la modalidad epistémica, entre otros recursos, para contextualizar la constitución de la identidad de experto.

Fitzgerald y Housley (2002) analizan un programa radial y sostienen que es posible examinar la forma en que las identidades son desarrolladas en conjunción con el fluir secuencial de la interacción, si se presta atención a la categorización y a la organización secuencial dentro de los medios de comunicación.

Gülich (2003) focaliza en la interacción cara a cara entre expertos y no expertos (médicos y pacientes): estudia los procedimientos de ilustración, tales como las distintas formas de lenguaje metafórico, distintas clases de ejemplificación, escenificación y otras formas de concretización, que son utilizados para explicar, ilustrar y aclarar, y analiza cómo estos son utilizados por los interlocutores con distintos fines. Asimismo, muestra cómo los roles de experto y no experto son constituidos en y por la interacción. En la misma línea, Ciapuscio (2003) estudia la constitución de las identidades de expertos (científicos) y legos a través del empleo de procedimientos de ilustración y reformulación: mediante el empleo diferencial de estos procedimientos y la modalidad específica que estos adquieren se constituyen interactivamente las identidades discursivas de experto y lego. 


\subsubsection{Sobre la alternancia de marcos.}

La alternancia de marcos humorísticos y marcos serios es uno de los recursos empleados por el entrevistador para lograr un efecto cómico y construir su identidad como ingenioso y transgresor. En la literatura sobre este tema que fue revisada surgieron como relevantes los artículos que mencionamos a continuación.

Con respecto al concepto de marcos, debemos destacar tres capítulos de Tannen (1993) que son especialmente relevantes para el tema que nos ocupa. Tannen y Wallat (1993) analizan una entrevista pediátrica, en la cual el cambio de marcos es generado por un desajuste en los diferentes esquemas de conocimiento (knowledge schemas) de los participantes de la interacción (la madre del paciente y el médico). Straehle (1993) contrasta dentro de una conversación entre amigos marcos serios y marcos en los que se bromea (teasing frames). Sugiere que el juego verbal en broma es una manifestación de la relación cercana que los participantes tienen entre sí. La interpretación del metamensaje "Esto es broma" se basa en el conocimiento compartido de pistas lingüísticas que poseen los hablantes. Por consiguiente, en vez de producir hostilidad el discurso antagonista envía un metamensaje de rapport y, entonces, no es soprendente que el acto de bromear esté en relación directa con el grado de cercanía de los participantes de la interacción. Schiffrin (1993) hace uso de conceptos tales como marcos, alineación de los participantes y despliegue de identidad, para analizar una movida interactiva particular: "hablar por el otro", que se observa particularmente en las entrevistas sociolingüísticas. El hablante que actúa como vocero de otro de los participantes de la interacción no solamente utiliza al otro como punto de partida para su próximo turno, sino que además penetra en la perspectiva del otro y se posiciona en ella para producir su próxima contribución. "Hablar por el otro" es una manera de ocupar el rol del otro. 


\subsubsection{Sobre la hipérbole y la ironía}

Tradicionalmente, la ironía ha sido entendida como una expresión en tono de burla de significación contraria a la del enunciado, que se pone de manifiesto por el contexto, la pronunciación, etc. La hipérbole, por otro lado, ha servido para dar énfasis, y se la ha considerado como una exageración extravagante que no se espera que sea entendida literalmente.

Las obras de referencia clásicas sobre los recursos retóricos ofrecen definiciones en general coincidentes sobre estos recursos (cf. Albadalejo, 1991; Barthes,1966; García Barrientos, 1998). Por el tipo de trabajo que emprendemos, sin embargo, nos han resultado especialmente relevantes dos trabajos que tratan la hipérbole y la ironía desde la perspectiva conversacional: se trata de McCarthy y Carter (2004) y Clift (1999).

McCarthy y Carter (2004) examinan los casos de hipérbole en un corpus de conversaciones cotidianas. La hipérbole se presenta en muchas ocasiones asociada a la ironía, pero en este artículo se la estudia en el contexto más amplio de aseveraciones exageradas que son utilizadas por los hablantes para producir numerosos tipos de significados interpersonales. Los autores enfatizan la naturaleza interactiva de la hipérbole: la reacción del oyente es crucial para su interpretación y además, el éxito de la hipérbole depende de que el oyente acepte concertar un pacto en el cual se permiten las formulaciones extremas y la creación de mundos imposibles.

Por otro lado, Clift (1999) propone la adopción del concepto de framing de Goffman para caracterizar la ironía en la conversación. Sugiere que el framing se logra con un cambio en el posicionamiento del hablante (footing shift). Este cambio permite al hablante utilizar la ironía para hacer evaluaciones en respuesta a transgresiones hechas por el interlocutor. Tanto la construcción de un turno irónico y su ubicación en una determinada secuencia hacen que el cambio de posicionamiento y el marco se hagan visibles. Este análisis muestra 
hasta que punto la ironía es afiliativa y revela diferentes grados de sutileza en el efecto y diversidad de actitudes que pueden expresarse a través de la ironía.

Los trabajos que comentamos han sido de gran utilidad para el estudio sobre las entrevistas que forman el corpus de esta tesis. En el capítulo siguiente presentamos los aspectos metodológicos y describimos con mayor detalle el corpus. 


\section{METODOLOGÍA Y CORPUS}

En este capítulo se establecerá, en primer término, la metodología que ha sido utilizada en el análisis de los textos y el procesamiento de los datos obtenidos. A continuación, se realizará una descripción detallada del corpus analizado en este trabajo y una caracterización general de la entrevista como género discursivo.

De acuerdo con los lineamientos teóricos escogidos, este trabajo tiene una orientación empírica. El análisis de los textos es de carácter predominantemente cualitativo, aunque hemos procedido a la cuantificación de algunas variables consideradas relevantes o salientes.

Los estudios etnometodológicos se han realizado tradicionalmente sobre textos orales de poca extensión, que en muchos casos fueron luego incorporados a un corpus de trabajo mayor. En su mayoría esos estudios han consistido en un análisis ejemplar de los textos. En nuestro caso, nos permitimos trabajar con un corpus relativamente extenso para otorgar mayor validez a nuestros resultados.

La investigación realizada se ordenó en las etapas canónicas de 1) lectura y análisis crítico de la bibliografía; 2) selección, ordenamiento y codificación de los materiales; 3 ) inmersión en el corpus y establecimiento de las tesis; 4) análisis de los materiales; 5) presentación y discusión de los resultados, y por último, 6) obtención de conclusiones.

Nuestro corpus está compuesto por 40 textos escritos correspondientes al "Reportaje Atrevido" de Jorge Guinzburg, publicado en algunos números de la revista Viva del Diario Clarín de los domingos, editado en Buenos Aires. Los textos fueron publicados entre los años 2000 y 2003. En estos reportajes, Guinzburg, un conocido periodista y conductor televisivo, entrevista a miembros de la "farándula" (actores, cantantes, modelos, etc.), deportistas, escritores y 
políticos, conocidos por el público local o que han adquirido cierta notoriedad en un período cercano al momento de la entrevista.

Antes de su publicación las entrevistas sufren un proceso de recontextualización para lo cual se las transcribe en forma regularizada, es decir, que se eliminan todos los signos de oralidad (con excepción de la risa, que es consignada entre paréntesis, algunas interjecciones 0 algunos indicadores de énfasis). Las contribuciones del entrevistador están diferenciadas de las del entrevistado por el uso de negrita en la impresión, mientras que las del entrevistado son consignadas en tipo de impresión normal. Acompañan al texto fotografías del entrevistado, una foto de J. Guinzburg junto al entrevistado, partes extractadas y resaltadas del texto y un titular con una frase clave del reportaje extraída de los dichos del entrevistado. ${ }^{9}$

La entrevista como género posee ciertas características que la diferencian de otros géneros discursivos. En la clasificación de Bajtin (1998:250) corresponde a los géneros secundarios que son elaborados a partir de los primarios, como por ejemplo, el diálogo, la narración, etc. La entrevista se asemeja, en primera instancia, a la conversación espontánea, aunque tiene características o convenciones propias que enumeramos a continuación:

- En primer lugar, la entrevista se caracteriza por la alternancia obligada de turnos (Arfuch, 1995:43), con marcada asimetría de roles. El marco de la entrevista otorga a los participantes ciertos derechos y atribuciones, pero también les asigna obligaciones. El entrevistador es quien pregunta y el entrevistado contesta, rara vez a la inversa. Los roles de entrevistador y entrevistado son fijos y están asignados de antemano. El entrevistador tiene derecho a preguntar sobre la vida del entrevistado y a manejar el curso de la interacción a través de los tópicos. El entrevistado debe contestar las preguntas

\footnotetext{
${ }^{9}$ La entrevista $N^{\circ}$ VIII que fue obtenida por medios electrónicos presenta una diagramación diferente.
} 
del entrevistador ${ }^{10}$, pero no puede por su parte hacer preguntas, por ejemplo, sobre la vida del entrevistador. A su vez, sus respuestas están constreñidas por las preguntas mismas, aunque ocasionalmente puede ser evasivo o negarse a contestar. ${ }^{11}$

- Entrevistador y entrevistado conocen las normas que rigen la entrevista (existen en los textos analizados numerosas pruebas de ello $)^{12}$. Deben atenerse a determinadas convenciones para que la entrevista sea reconocible como tal. Sin embargo, se producen a veces variaciones 0 infracciones ${ }^{13}$ que producen distintas consecuencias discursivas y que son consideradas como transgresiones a la norma.

- La entrevista sugiere autenticidad porque se establece un juego de presencia y de relación directa entre los participantes, que interactúan cara a cara. Entre entrevistador y entrevistado existe un pacto o contrato por el cual se comprometen a revelar la verdad ${ }^{14}$; este es el fin último de la entrevista (cf. Presentación, de Beatriz Sarlo en Arfuch, 1995:13; Clayman \& Heritage, 2002:29). Ésta será presentada al tercer integrante de este evento de habla: el público lector, que constituye el tercer vértice de este triángulo discursivo.

- El público lector no está presente en la interacción. Solamente accederá en forma diferida a una versión escrita (en nuestro caso) de la entrevista. Sin embargo, la interacción se orienta hacia este tercer participante y es moldeada en función de él. (cf."presumed audiences", Jaffe, 2000:40; Clayman \& Heritage, 2002:120) .

\footnotetext{
${ }^{10}$ Cf. [VII 81/82]

${ }^{11}$ Cf. [X II 23]

${ }^{12}$ Cf. [X IX 31/32]

${ }^{13} \mathrm{Cf} .[X X X I X 1 / 4]$ y [III 49]

${ }^{14}$ Cf. [X 15] y [XXII 20]
} 
- El contenido temático de las entrevistas está en general comprendido por los datos biográficos del entrevistado, que se erige en foco de la entrevista. La interrogación por parte del entrevistador logra obtener diferentes relatos del entrevistado que conforman piezas del rompecabezas de su historia personal y su personalidad (Arfuch, 1995:92). La entrevista crea un nexo entre el sujeto privado con historia y la personalidad pública que está signada por esa historia, y a su vez permite el acercamiento del entrevistado a la audiencia (cf. Presentación, de Beatriz Sarlo en Arfuch, 1995:14)

- Los temas no son negociados por los interactuantes como en la conversación espontánea. Es el entrevistador quien maneja los tópicos a través de las preguntas. Hay amplia evidencia ${ }^{15}$ en nuestro corpus de que el entrevistador conoce de antemano algunos datos de la vida del entrevistado y los utiliza como recurso para obtener más datos. Ocasionalmente el entrevistado se niega a contestar alguna pregunta y en este caso puede producirse una negociación del tópico. ${ }^{16}$

- El lenguaje de la entrevista presenta gran flexibilidad, que puede abarcar desde extrema formalidad a usos coloquiales, según los marcos que se crean en la entrevista. En nuestro caso, el uso de un determinado léxico o registro por parte del entrevistador es uno de sus recursos para construir una cierta identidad para sí mismo y ubicar al otro en determinada posición.

Los hablantes de una comunidad poseen cierto saber sobre clases textuales o estructuras globales textuales (Heinemann \& Viehweger, 1991). Las clases textuales son clasificaciones empíricas realizadas por los miembros de una comunidad de habla. En el corpus bajo análisis existen numerosas

\footnotetext{
${ }^{15}$ Cf. [XXIII 43] y [XXIV 11]

${ }^{16}$ Cf. [XVI 32/36]
} 
instancias en las cuales los participantes manifiestan conocer qué clase textual se está desarrollando y cuáles son sus normas o convenciones, y por ende, cuándo se las está infringiendo. Según Gülich, ${ }^{17}$ las clases textuales no son marcos de orientación rígidos para los participantes de la conversación, sino que son constituidas por los hablantes durante la interacción comunicativa en forma interactiva.

En su clasificación de tipos textuales Heinemann y Viehweger (1991) ${ }^{18}$ proponen una diferenciación de las clases textuales o géneros según los siguientes parámetros: I) tipos de función, II) tipos de situación, III) tipos de procedimientos, IV) tipos de estructuración textual y V) esquemas de formulación prototípicos; tales parámetros permitirían realizar un ordenamiento y una clasificación multidimensional de los textos.

Si intentáramos una caracterización de la entrevista periodística escrita siguiendo los lineamientos de Heinemann y Viehweger podríamos decir que en el nivel I la entrevista cumple la función de obtener información para difundirla al lector y en nuestro caso, simultáneamente, tiene el propósito de entretener y divertir. En cuanto a la situación (nivel II), se da en un contexto institucional. La entrevista es una forma mediática convencional para difundir información sobre personas o temas determinados, ya sea en forma oral o escrita. En este caso la comunicación es cara a cara con el interlocutor (en general diádica) y a distancia de la audiencia lectora. Existe marcada asimetría de roles entre entrevistador y entrevistado ${ }^{19}$. En el nivel III, la entrevista se caracteriza por su desarrollo en forma de secuencias dialogales ${ }^{20}$ en las cuales prima la interrogación por parte del entrevistado. En el nivel IV encontramos un núcleo textual que está constituido por el cuerpo de la entrevista, y generalmente una parte inicial y una parte terminal. En nuestro caso, en el cual la entrevista ha

\footnotetext{
${ }^{17}$ En Ciapuscio (1994: 59)

${ }^{18}$ En Ciapuscio (1994:100 y ss.)

${ }^{19} \mathrm{Cf}$. caracterización del género, supra.

${ }^{20}$ La noción de "secuencias dialogales" de J.M Adam (1991) resulta útil aquí, aunque su concepción abstracta del texto no coincide con nuestra perspectiva del texto como un fenómeno dinámico.
} 
sido recontextualizada, la parte inicial está compuesta por el título y las frases extraídas del texto. En cuanto al nivel $\mathrm{V}$, correspondiente al estilo y la formulación lingüística, Heinemann y Viehweger sostienen que los diferentes tipos textuales pueden incluir constituyentes textuales estereotipados. En el caso de la entrevista periodística suelen presentarse en el nivel del formular determinados tipos de preguntas que pueden asociarse típicamente al género entrevista. Presentaremos los resultados relevantes con respecto a este nivel en la sección analítica. 


\section{B. SECCIÓN ANALÍTICA}

En esta sección presentamos el análisis de los datos del corpus, que tiene por propósito mostrar cómo los participantes de la entrevista construyen en forma interactiva su identidad discursiva mediante distintos procedimientos, y al mismo tiempo hacer un relevamiento del repertorio de recursos discursivos, retóricos y lingüísticos que los hablantes emplean con esa finalidad durante la entrevista periodística de humor.

Los ejemplos citados fueron extraídos de los textos I a XL que se encuentran en el Apéndice. Los números arábigos empleados en cada ejemplo corresponden a los pares adyacentes. Las tablas I, II y III (ver en Apéndice) contienen los datos sintetizados y esquematizados sobre los marcos de humor, la selección léxica y las fórmulas de tratamiento, que serán analizados dentro de los capítulos 4 y 6 .

El análisis que se efectuará a continuación gira alrededor de dos ejes principales:

a) la construcción de la identidad del entrevistador por medio de su condición de performer, focalizando, en primer término, sobre la alternancia estratégica de marcos de humor y marcos serios como principal recurso identitario, y además, sobre el uso de figuras retóricas, recursos discursivos generales y lingüísticos (capítulo 4)

b) la construcción de la identidad del entrevistado a través de procesos de auto y heterocategorización (capítulo 5)

Como se ha observado en el corpus bajo análisis el entrevistador se erige como performer frente al entrevistado y la audiencia lectora. Por medio de distintos recursos logra realizar un trabajo discursivo identitario en el cual 
involucra a su entrevistado, que se transforma en una pieza clave para la constitución de la identidad discursiva del entrevistador (capítulo 4)

Como se desprende de la literatura tradicional que ha abordado el tema, el locus de la identidad en el discurso ha sido ubicado principalmente en los procesos de categorización y en el uso de ciertos pronombres (por ejemplo, "nosotros" y "ellos"). En nuestro corpus surgen como relevantes los procesos interactivos de categorización, por medio de los cuales se constituye la identidad del entrevistado (capítulo 5). Esos procesos, simultáneamente, influyen en la constitución de la identidad del entrevistador.

Asimismo, resultan llamativas las formas de tratamiento pronominal usted y vos, que constituyen las dos formas del paradigma local utilizadas por los hablantes para dirigirse al otro, relacionadas con los ejes de poder y solidaridad (Brown \& Gilman, 1968) que a su vez entran en juego con ciertas variables intervinientes tales como edad, clase social, estatus, etc. Analizaremos la manera en que las formas de tratamiento colaboran en la constitución de la identidad discursiva de los interlocutores (capítulo 6).

Las entrevistas constituyen una arena, donde entrevistador y entrevistado disputan un duelo identitario marcado por el empleo de ciertas formas y recursos típicos. El entrevistador tiene derecho a la primera estocada, ya que le corresponde tomar el turno de apertura de la entrevista. El entrevistado responde eligiendo una de las alternativas a su disposición, pero su elección está siempre condicionada a la elección hecha previamente por el entrevistador.

En los capítulos 4 y 5 presentaremos el análisis de la construcción de las identidades discursivas de entrevistador y entrevistado en secciones separadas para mayor claridad y precisión. No obstante, y como ya se ha mencionado con anterioridad, coincidimos en la visión de la constitución de la identidad discursiva como un proceso colaborativo llevado a cabo por los participantes de la interacción. Es impensable que uno de ellos pueda actuar 
en forma independiente, ya que cada uno cumple un rol determinado con respecto al otro y ambos son mutuamente indispensables. El focalizar sobre un participante a la vez nos permitirá tener una visión más inmediata y acotada de los procesos involucrados en el trabajo identitario de cada uno de ellos, sin que por esa razón se pierdan de vista los procesos que atañen a la constitución de la identidad del otro participante. 


\section{LA IDENTIDAD DEL ENTREVISTADOR}

\subsection{Alternancia de marcos}

En las entrevistas que analizamos pueden identificarse numerosos marcos serios en los cuales se habla de diferentes tópicos. Alternando con ellos tienen lugar los marcos de humor, que varían en extensión, desde una emisión a una secuencia de emisiones, a lo largo de varios turnos.

La alternancia de marcos es empleada por el entrevistador como recurso estratégico para construir su identidad. En determinados momentos el entrevistador hace bromas empleando ciertos recursos discursivos, retóricos y lingüísticos, que constituyen un marco de humor. No se ha encontrado en el corpus analizado un patrón que permita localizar momentos específicos dentro de la interacción en los cuales se produce el cambio de marco, ni señales particulares disparadoras de este mecanismo. ${ }^{21} \mathrm{El}$ entrevistador no tiene una agenda prefijada con respecto al empleo de este recurso, sino que más bien utiliza las oportunidades de desplegar su creatividad lingüístico discursiva a medida que se presentan en el fluir de la interacción. Para tal efecto necesita de la colaboración del entrevistado quien contribuirá a que el marco de humor se constituya como tal. El entrevistado puede prestarse al juego continuando el marco de humor, reírse o ignorar la broma en forma voluntaria o involuntaria.

Si bien en las entrevistas analizadas hay numerosos aspectos que son predecibles como la distribución de roles, la alternancia obligada de turnos y los temas tratados, el número total de marcos humorísticos presentes en cada entrevista no lo es, ya que depende del curso que tome la interacción y de la negociación de la interacción que tenga lugar entre los participantes.

El número de marcos humorísticos varía de entrevista en entrevista. ${ }^{22}$ En general, el promedio de marcos de humor presentes en una entrevista

${ }^{21}$ Cf. Straehle (1993) 
oscila entre 7 y 22, con algunas excepciones en las cuales se halla presente un número mayor (hasta 32). Cuanto mayor es el número de marcos de humor, mayor es el despliegue de la identidad discursiva del entrevistador. Por otro lado, en aquellas entrevistas en las cuales el número de marcos de humor es bajo (por ejemplo entrevistas XIII, XXIX y XXV), el entrevistador logra un menor despliegue de esa identidad. En estos casos y como contrapartida, la identidad del entrevistado parece proyectarse en forma sobresaliente, mientras que la identidad del entrevistador se retrae de la escena.

El entrevistador despliega su identidad discursiva no solamente ante su interlocutor del momento, sino que también lo hará en forma diferida ante los lectores de la revista para quienes la entrevista será plasmada en papel. El efecto humorístico producido principalmente por la alternancia de marcos y también por la puesta en uso de los otros recursos mencionados llegará finalmente a los lectores, quienes obtendrán una visión global de la entrevista, distinta de la percepción paso a paso que obtienen los participantes. Aun en aquellas instancias en las cuales el entrevistado no ha captado el humor generado por el entrevistador, los lectores podrán, según su grado de competencia, comprenderlo y disfrutarlo.

Si bien sostenemos que es el entrevistador quien construye su identidad discursiva a través de la alternancia de marcos, el entrevistado no permanece al margen de este proceso; por el contrario, juega un papel crucial en la construcción de los marcos de humor y por lo tanto en la conformación de la identidad del entrevistador. Sin su colaboración no sería posible llevar la interacción hacia adelante.

El tipo de entrevista analizada está inserta en un marco mayor que está señalado desde su comienzo por el nombre de la sección de la revista: Reportaje Atrevido. Éste indica que no se trata de una entrevista convencional, sino de una en la cual se transgreden ciertas normas impuestas para este

${ }^{22}$ Cf. Tabla de datos I 
género: la seriedad, los límites de la corrección, etc. Esto otorga al entrevistador ciertos derechos ventajosos como, por ejemplo, preguntar sobre la vida íntima de los entrevistados y transgredir las normas sin ser cuestionado. A lo sumo el entrevistado podrá negarse a contestar, pero nunca enojarse por el tema o el tenor de la pregunta. Dentro de este marco mayor, que los entrevistados conocen de antemano, se conduce la entrevista. Los marcos de humor son en cierta forma esperados y el entrevistado los toma como tales y en la mayoría de los casos sigue el juego del entrevistador, creando una atmósfera de cooperación.

El marco dentro del cual actúan los interlocutores prevé la ocurrencia de secuencias de humor y secuencias serias. El entrevistado sabe que lo que se dice en ocasiones no es dicho en serio y que no tiene sentido ofenderse cuando es blanco de una broma. Preserva su imagen ya que la broma puede constituir una amenaza a la misma y permite que la entrevista fluya normalmente. Esto hace que entrevistado y entrevistador se alineen como participantes de un mismo evento de habla y se cree rapport en vez de alejamiento.

Los ejemplos 1 y 2 que presentamos a continuación muestran cómo los participantes construyen un marco de humor en forma conjunta, que a su vez contribuye a la constitución interactiva de la identidad del entrevistador, y muestra al entrevistado como un participante alineado con su interlocutor.

\section{Ejemplo 1}

$\mathrm{JG}^{23}:$ ¿Se mudaron?

Eo: ${ }^{24}$ No, seguimos viviendo en casa. Le hicimos algunas refacciones.

JG: Le agregaron apenas seis pisos.

23 JG: Jorge Guinzburg

${ }^{24}$ Entrevistado 
Eo: Seis pisos, ascensor, piscina climatizada. No, lo principal fue poner rejas, porque la gente cada vez que venía a Luján hacía la Basílica y la casa de Luciano Pereyra ${ }^{25}$, como en un tour......

JG: Rejas y la boletería para cobrar la entrada.

Eo: Dos pesitos más IVA estamos cobrando, y se llevan la imagen de la Virgen y la imagen de Luciano Pereyra bendecida por Luciano Pereyra.

$[X X X \mid 18 / 20]$

El entrevistador formula una pregunta y luego de la respuesta del entrevistado, hace un chiste utilizando una hipérbole "le agregaron apenas seis pisos", que es continuada por el entrevistado en el turno siguiente "seis pisos, ascensor". La hipérbole va in crescendo y se desarrolla en los dos turnos siguientes en los cuales, a partir de la creación de un "escenario" o escenificación (Gülich, 2003) la casa se expande y se transforma, como la Basílica de Luján, en una especie de santuario, al cual la gente llega en grupo, y donde se cobra entrada y se venden recuerdos. El escenario creado por los interlocutores cobra vida y crece en cada turno para ser luego recreado por los lectores, quienes podrán fácilmente decodificar las imágenes, asociándolas a otras similares en su experiencia. Los participantes construyen en forma colaborativa un marco de humor, apoyándose sucesivamente en la contribución del otro y dando muestra de su experticia como hablantes.

A continuación citamos otro caso de similares características.

\section{Ejemplo 2}

JG: ¿Pensás terminar la secundaria?

Eo Lo tengo que ver.......

JG: Tenés que aprovechar ahora, porque ¿quién te va a bochar?

Eo: $\quad$ Si no aprovecho ahora no aprovecho más...(se ríe)

JG “Uy, lo boché a Nalbandian ${ }^{26}$, le puse un dos en gimnasia”.

\footnotetext{
${ }^{25}$ Luciano Pereyra es un cantante joven.
} 
Eo: $\quad$ Callate que un año me la hicieron llevar, porque no fui a una sola clase.

JG: El profesor de geografía no puede ponerte un dos; le decís: "No, no es como dice en el libro, yo sé porque estuve."

Eo: Claro, "yo estuve y no es así, usted está equivocado."

[XXXIV 77/79]

En este ejemplo el entrevistador le sugiere al entrevistado que sería ventajoso terminar la secundaria ahora que es famoso porque ningún profesor lo desaprobaría. El entrevistado ratifica lo dicho y se ríe. El entrevistador continúa la secuencia creando una vez más un "escenario" en el cual un profesor desaprueba a Nalbandian en la materia en la que ha tenido seguramente mejor desempeño, y el entrevistado, por su parte, aporta una anécdota que muestra que lo imaginado ya le ha sucedido. El entrevistador, utilizando el estilo directo, pone en boca del entrevistado lo que éste debería decir; el entrevistado ratifica y con el mismo recurso hace hablar al personaje que lo representa, continuando la secuencia de humor. El resultado que produce esta secuencia es una actividad discursiva colaborativa, en la cual los participantes se apoyan en la contribución del otro para construir el discurso y llevar la interacción hacia adelante.

Este tipo de secuencias de humor ocurre con relativa frecuencia en las entrevistas y en varias ocasiones, como en los ejemplos, se extiende a lo largo de varios turnos. Esto es evidencia de la negociación conjunta de la interacción y ratifica la identidad del entrevistado como ingenioso. También muestra al entrevistado como un interlocutor capaz de comprender el tipo de humor empleado y de replicarlo en forma competente, utilizando los mismos recursos que el entrevistador.

Sin embargo, se dan otros casos en los que, por ejemplo, el doble sentido o la ironía son ignorados y la secuencia de humor se cierra abruptamente para retornar al marco serio. En negrita indicamos las partes relevantes.

${ }^{26}$ El entrevistado, David Nalbandian, es un conocido tenista argentino. 


\section{Ejemplo 3}

JG: Hay una escena de El exilio de Gardel que no la puedo olvidar.

Eo: Bueno, ahí todo el mundo creo que se impresionó. Hombres y mujeres.

JG: Muy interesante tu actuación.

Eo: Mirá no se si era muy interesante mi actuación en esa película.

JG: Hubo una escena muy fuerte, siento que le pusiste el pecho a tu papel.

Eo: Me parece que esa escena fue muy fuerte porque veníamos de una dictadura muy grande y era una especie de destape en las películas. Ahora todos están en bolas.

[XXXVII 87/ 89]

El entrevistador comenta irónicamente sobre la actuación de la entrevistada (Gabriela Toscano ${ }^{27}$ ) en una película como "muy interesante". Ella pone en duda que su actuación haya sido muy interesante y no toma como broma lo dicho por el entrevistador, ni tampoco como un cumplido. Al no ser interpretada como ironía por el interlocutor, la frase pierde su valor y es neutralizada. En el turno siguiente el entrevistador insiste en continuar con el marco de humor que amenaza con cerrarse y emplea una frase con doble sentido: "poner el pecho al papel" (refiriéndose al desnudo que la actriz hace en la película y a la idea de poner empeño o esfuerzo al hacer algo). La entrevistada desvía nuevamente el curso del marco de humor iniciado por el entrevistador. De esta manera, se corta abruptamente la secuencia de humor y se retorna al marco serio. Hay evidencia de que la entrevistada capta el doble sentido y continua el tópico en el sentido del desnudo pero no en broma.

En otros casos el entrevistado no percibe inmediatamente que el entrevistador ha iniciado un marco de humor y la captación se produce en forma retardada. En el ejemplo que transcribimos a continuación, la entrevistada, la actriz Soledad Silveyra, está hablando de una obra de teatro que protagoniza:

${ }^{27}$ Actriz argentina 
Ejemplo 4

JG: ¿Son sólo dos actores en escena?

Eo: Son dos actores en 10 escenas.

JG: ¿Con monólogos o con interrelación?

Eo. Con interrelación. Están el taxista y la prostituta y entra la francesa, se va el taxista y entra el estudiante, todo en un solo acto (...) Es un trabajo muy difícil.

JG: Muy difícil pero la están pasando bárbaro en el escenario.

Eo: Por lo menos la pasamos bárbaro como compañeros de trabajo.

JG: Me imagino

Eo: ¡Ah! No había caído (Risas) No te creas, en el escenario todo es más difícil.

[l 16/19]

El entrevistador intenta iniciar un marco de humor empleando la palabra "interrelación" con doble sentido (relación entre dos o más cosas o personas y relación sexual). La entrevistada responde utilizando la misma palabra pero en el primer sentido, sin dar señal de haber captado la doble intención. En el turno siguiente el entrevistador insiste en imprimirle al tema un matiz sexual: "la están pasando bárbaro", pero la entrevistada continua sin captar la verdadera intención de lo dicho. Sólo cuando el entrevistador dice "me imagino", la entrevistada se da cuenta de que la secuencia precedente tenía una carga de humor que ella no ha interpretado. La risa en este caso indica entendimiento y afiliación entre los participantes.

Para que la secuencia de humor sea efectiva, ésta debe ser iniciada por uno de los interlocutores y luego ratificada por el otro, ya que es a través de estos procesos interactivos que se negocian los significados en la interacción.

En la sección siguiente analizaremos los recursos más salientes que permiten al entrevistador crear marcos de humor. 


\section{2 Figuras retóricas, estrategias discursivas generales y recursos lingüísticos.}

Como dijimos anteriormente el entrevistador se posiciona como performer frente al entrevistado y a la audiencia lectora. Crea una dramatis persona que actúa por él y que es puesta en acción en cada entrevista. Para esta actuación el entrevistador utiliza un estilo particular de habla, que se caracteriza por el ingenio, es decir, la habilidad de realizar conexiones entre ideas rápidas, brillantes e imaginativas, cristalizadas en diferentes figuras retóricas y otras estrategias discursivas. Consignaremos las más salientes, es decir las que se presentan con mayor asiduidad en nuestro corpus. Estos recursos contribuyen a crear el efecto humorístico que a su vez configura la identidad discursiva del entrevistador.

Por otra parte, hemos encontrado que estos recursos actúan como verdaderas pistas de contextualización, en el sentido de Gumperz (1982). El hablante debe afirmar continuamente el rol que ocupa en la interacción (Auer, 1992:27) utilizando pistas de contextualización. En el caso del entrevistador, éste afirma su identidad discursiva por medio de figuras retóricas y diversas estrategias discursivas que conforman los marcos de humor. El entrevistador envía por medio de ellas un metamensaje a su interlocutor y a su audiencia lectora que dice "Esto es broma", y que obtura cualquier efecto hostil potencial hacia el entrevistado. Por lo tanto, los recursos empleados por el entrevistador poseen una triple función discursiva: en primer lugar, proveen un marco de interpretación para las emisiones que ocurren dentro de los marcos de humor; segundo, neutralizan cualquier posible efecto agresivo hacia el interlocutor; por último, contribuyen a moldear la identidad del entrevistador.

Las figuras retóricas, las estrategias discursivas generales y los recursos lingüísticos más frecuentes empleados por el entrevistador dentro de los marcos de humor para construir su identidad como gracioso e ingenioso serán analizados en las secciones siguientes. 


\subsubsection{Figuras retóricas clásicas}

Dentro de los recursos clásicos se destacan el uso de la ironía y la hipérbole.

\section{IRONÍA}

En su sentido más amplio la ironía es el reconocimiento de la incongruencia entre la realidad y la apariencia. Hay un desdoblamiento de lo que realmente es y lo que aparenta ser. En general, lo que se afirma es lo opuesto de lo que realmente se quiere decir. Según García Barrientos (1998:56), la ironía es una expresión en tono de burla de una significación contraria o diferente a la del enunciado, que se pone de manifiesto por el contexto, la pronunciación, etc.

Distinta de esta perspectiva tradicional es la visión de la ironía a la que adhiere Clift (1999). Esta autora sostiene que teniendo en cuenta el concepto de framing de Goffman puede capturarse la presencia de dos dimensiones de significado en la ironía: uno exterior y uno interior, el uno enmarcando al otro. Estos dos aspectos deben ser percibidos simultáneamente para poder comprender una emisión irónica. Sostiene además que el framing se logra con un cambio de posicionamiento del emisor, quien de esa manera puede hacer evaluaciones en respuesta a determinadas transgresiones cometidas por el interlocutor durante la interacción. En esta visión interactiva de la ironía es crucial la reciprocación de la emisión irónica por parte del interlocutor tanto a través de la risa como de la producción de una emisión irónica similar o de un comentario literal que indique recepción del intento irónico del hablante.

A continuación citamos ejemplos de emisiones irónicas (indicadas en negrita) en su contexto de uso. 
Ejemplo 5

JG:¿ Está embarazada tu nuera?

Eo. No, pero espero que me la embarace.

JG: ¡Querés que cometa los mismos errores que vos!

Eo: Siempre les digo "Ustedes cásense, total después estoy yo para cuidar al chico"

JG: Mirá que divina que sos.

Eo: Muero por una personita chiquitita en la familia. Muero.

JG: $Y$ adoptá un nene, pero no jorobés a tus hijos.

El entrevistador no dice lo que realmente piensa en forma directa. Por medio de la ironía implica lo contrario de lo que realmente está diciendo: en este caso deja ver que opina que la entrevistada no está actuando desinteresadamente sino que, por el contrario, su actitud es egoísta y que sólo desea satisfacer sus propios deseos. García Barrientos (1998:57) encuadra ejemplos como éste dentro de una variedad de ironía llamada asteísmo en la cual se enuncia una alabanza ("que divina que sos") pero la intención real es de reprensión. La entrevistada ve su imagen amenazada a través de la ironía y en el turno siguiente utiliza dos diminutivos "personita chiquitita" en un intento de provocar ternura y de borrar la imagen de persona egoísta. El entrevistador no le permite hacer esto, sugiriendo un camino alternativo por medio del cual la entrevistada podría satisfacer sus deseos sin importunar a los demás.

\section{Ejemplo 6}

JG: ¿Cómo eras de chiquitita?

Eo. Mi abuela contaba que andaba siempre con la cola al aire. Era bastante exhibicionista de niña; yo me paseaba por la casa y mi abuelo me decía: "Solita no seas impúdica", y yo le decía :"Tata yo mujer puta no."

JG: Es muy tierno, muy literario. 
Eo: Era una niña que sufría mucho, tuve una madre enferma mucho tiempo, que acabó en un suicidio.

Por medio de la ironía el entrevistado señala que lo que la entrevistada dice no es tierno ni literario. Lo que podría constituir un emotivo recuerdo de la infancia se ve distorsionado por el uso de un vocablo vulgar. La entrevistada se posiciona como una niña de corta edad (ella misma) quien posiblemente no conoce el registro de la palabra vulgar que usa. El uso del estilo directo la exime de toda responsabilidad sobre lo dicho y le permite distanciarse: es la niña quien dice eso, no la persona adulta. Sin embargo, mediante la ironía, el entrevistador le habla a la entrevistada adulta, haciendo caso omiso del hecho de que son los dichos de una niña en boca de un adulto, y la reprende solapadamente por usar un termino vulgar, que no sería apropiado en una entrevista. Al mismo tiempo, el entrevistador le habla a la entrevistada como adulta pero la reprende como si fuera una niña, en un juego de roles que produce un efecto gracioso. La ironía en este caso tiene entonces una fuerza ilocutiva múltiple: expresa lo que el hablante realmente siente o pretende sentir, recrimina o reprende al interlocutor y establece un marco de humor. Al final del intercambio, la entrevistada hace referencia a su niñez difícil en un intento de conmover a la audiencia y de posicionarse nuevamente como adulta.

\section{Ejemplo 7}

Eo: [....] Tampoco quiero entrar en polémicas, pero Cavallo nunca quiso a la Ciudad de Buenos Aires. Siempre la despreció.

JG: Con esto que dice se nota que Ud. tampoco quiere entrar en polémica.

Eo: Es verdad. Como él era del interior decía: “iLos porteños son unos privilegiados!" 
Los dichos del entrevistado están introducidos por un atenuante "Tampoco quiero entrar en polémicas" que estratégicamente anticipa una emisión que puede resultar controvertida. Este es un recurso frecuente en la conversación que es utilizado como atenuante y que muchas veces entra en contradicción con lo que se dice a continuación ("pero..."). El interlocutor normalmente no hace comentarios sobre esta posible incoherencia por parte del hablante. En este caso el entrevistador llama la atención sobre la aparente contradicción, utilizando la ironía a la cual incorpora parte de los dichos del entrevistado. El resultado es que el entrevistado aparece justamente como iniciando una polémica sobre el tema aunque lo niegue. Al final del intercambio el entrevistado afirma que lo que dice sobre su rival es verdad, con lo cual intenta reafirmar el hecho de que él no quería iniciar polémica sino establecer la verdad.

\section{Ejemplo 8}

JG: Si vas a Miami ¿no es lógico que te quieran sacar alguna fotito?

Eo: Me voy para que no me saquen fotos; me voy para descansar afuera.

JG: Si vas a Alaska no te van a sacar fotos.

Eo: Voy a tener que irme a Alaska.

JG: ¡La vas a pasar tan bien!

Eo: Por eso tomé como decisión hacer notas únicamente para hablar de proyectos inmediatos. No sobre mi vida privada .....

Con respecto a la persecución de los medios gráficos el entrevistador sugiere que el entrevistado se vaya a un lugar bien remoto como Alaska. El entrevistado adhiere a esto y luego el entrevistador comenta irónicamente mediante una cláusula exclamativa que la va a pasar muy bien, implicando exactamente lo contrario. La emisión es entendida como ironía a través del conocimiento del mundo que tienen los hablantes: Alaska es un lugar muy frío e inhóspito y por ende, no muy agradable para vivir. 
En algunos casos para producir el efecto irónico el entrevistador utiliza una interrogación retórica:

\section{Ejemplo 9}

Eo: [...] Educ. ar es un proyecto que pretende democratizar la educación. Que todos los chicos del país, pobres o ricos, tengan la capacidad de acceder, por primera vez, a los mismos contenidos. $Y$ esto te lo puede permitir Internet [...] capacitar a los docentes para que aprendan a manejar la tecnología y conectar a todas las escuelas del país.

JG: ¿No sería bueno que llegue la luz eléctrica también?

Eo: El ministerio de Educación trabaja en poner la luz, mejorar los pupitres.....

El entrevistado comenta sobre un proyecto del gobierno que pretende implementar adelantos tecnológicos en sectores carenciados. En nuestro país es común que el gobierno prometa concretar proyectos de esta naturaleza para rédito propio, sin pensar en garantizar elementos básicos tales como, en este caso, la provisión de electricidad. El entrevistador señala que, en todo caso, sería necesario que las escuelas carenciadas tuvieran luz eléctrica para poder implementar la tecnología. Su pregunta entraña en realidad una afirmación a la que nadie podría oponerse. El efecto irónico se produce a través de la explicitación de necesidades elementales no cubiertas. El entrevistado produce un comentario literal al final del intercambio en el cual afirma que el gobierno está trabajando en la provisión de luz.

Ejemplo 10

Eo: Sí de chica quería ser monja....jTodas queremos ser monjas! Viste que tenemos esa cosa de ....no sé .....de casarte con Dios.

JG: Yo imaginaba que tenía que ver con el deseo de cambiar el mundo, darle justicia, luchar para que nadie tenga hambre. 
Eo: Sí. Creo que tiene que ver con eso.

[XXXVII 32 / 33]

La entrevistada comenta que cuando era más joven, ella quería ser monja. Al tratar de explicar las razones de su deseo sugiere que todas las jóvenes lo desean y la razón es porque quieren casarse con Dios. El entrevistador enumera a continuación las razones que tradicionalmente han estado ligadas a la vocación religiosa, como el deseo de ayudar a otros, hacer justicia, etc. De esta manera lo dicho por la entrevistada es puesto en ridículo como poco serio, superficial e infantil. El entrevistador utiliza la ironía para crear un contexto en el cual la imagen de la entrevistada se ve seriamente amenazada al ser despojada de su condición de adulta y reprendida críticamente como si fuera una adolescente por su superficialidad y falta de compromiso social.

El uso de la ironía permite al entrevistador juzgar críticamente lo dicho por el entrevistado, ya sea recriminándolo o en tono moralizante, queriendo decir "Así es como debería ser". La ironía no resulta ofensiva en este caso porque el entrevistador habla por boca de su personaje, que está autorizado por la audiencia a realizar esos comentarios.

\section{HIPÉRBOLE}

La hipérbole es un recurso clásico para dar énfasis o producir un efecto humorístico. Consiste en una exageración extravagante que no se espera que sea entendida literalmente. García Barrientos (1998:54) afirma que la hipérbole es una sustitución de significados con exageración que rebasa llamativamente los límites de lo verosímil.

McCarthy y Carter (2004) estudian la naturaleza interactiva de la hipérbole y sostienen que la reacción del oyente es crucial para la interpretación y el éxito de la hipérbole en un determinado contexto. Con frecuencia los hablantes hacen aseveraciones exageradas o literalmente 
imposibles durante una narración o descripción. Esas expresiones hiperbólicas no son cuestionadas por los oyentes, quienes las aceptan como intensificaciones creativas con propósitos afectivos o evaluativos.

A continuación citamos algunos ejemplos de hipérbole (emisiones en negrita) que ocurren en nuestro corpus.

\section{Ejemplo 11}

Eo: ...seguimos viviendo en casa. Le hicimos algunas refacciones.

\section{JG: Le agregaron apenas seis pisos}

Eo: Seis pisos, ascensor, piscina climatizada.

[XXXI $18 / 19]$

El entrevistador utiliza una hipérbole para expandir lo dicho por el entrevistado en forma graciosa. El uso de "apenas" entra en contradicción con "seis pisos" que resulta excesivo para una casa de familia. El entrevistado colabora agregando elementos que amplían la escena y que transforman la casa original en una mansión. La frase inicial del entrevistado "le hicimos algunas refacciones" resulta entonces ridículamente graciosa en este nuevo contexto.

Ejemplo 12

JG: Si todos los diarios te pusieran en su primera plana mañana, ¿qué te gustaría que dijeran?

Eo : Que estoy haciendo una obra de teatro. (...)

JG: ¿Nada más?.

Eo: Nada más.

JG: "Record histórico", ¿por ejemplo?

Eo: No, no.

JG: "Obra de teatro es trasladada a estadio para que la puedan ver todos..."

Eo: (Se rie) 
Mediante el uso de la hipérbole, el entrevistador exagera la importancia de la obra de teatro y la cantidad de espectadores que asiste a la misma, en una secuencia que va en aumento hasta provocar la risa de la entrevistada. El entrevistador juega, además, con la creación de un escenario donde se evocan los titulares de un diario que anuncian la obra de teatro. La frase "record histórico" está conformada por un sustantivo + un adjetivo calificativo y "obra de teatro es trasladada..." está constituida por un sintagma nominal sin determinante + voz pasiva. Estos esquemas léxico sintácticos remedan las formulaciones prototípicas empleadas en los titulares de los diarios. El humor se crea en este caso a partir de una combinación del uso de la hipérbole con el conocimiento compartido de clases textuales por parte del entrevistado y la audiencia.

\section{Ejemplo 13}

JG: ¿La situación económica de la familia era buena?

Eo: Mas o menos [....] El departamento donde vivíamos tenía 60 metros cuadrados. Y entrábamos los cuatro y la perra.

JG: Que era la que dormía en el dormitorio principal.

Eo: $\mathrm{Si}$, era la que ocupaba más espacio, además.

JG: Para colmo tenían un San Bernardo.

Eo: Por suerte era un salchicha.

[XXXV 34/36]

El entrevistado describe su situación familiar cuando era más joven. La vivienda en la que vivía con su familia y su perro era muy pequeña. El entrevistador sugiere que el animal ocupaba la mejor habitación de la casa, lo cual es ratificado por el entrevistado quien dice que efectivamente la mascota ocupaba mucho lugar. Esto da pie al entrevistador para afirmar (sin tener conocimiento alguno del caso) que el perro en cuestión era un San Bernardo, es decir un animal de gran tamaño. Su emisión se inicia con la frase "para colmo" que típicamente anticipa que lo que sigue estará fuera de proporción de 
toda expectativa creada. El entrevistado realiza un comentario literal diciendo que el perro era en realidad un "salchicha" es decir, un animal pequeño.

La hipérbole permite al entrevistador generar humor mediante aseveraciones exageradas con las que, como se observa en los ejemplos extraídos de nuestro corpus, contribuye al discurso del entrevistado. Para que la hipérbole sea efectiva como recurso discursivo el hablante necesita de la colaboración de su interlocutor para la interpretación y aceptación de los mundos irreales creados en el fluir del discurso.

\section{2. 2 Estrategias discursivas generales}

Además de las figuras retóricas clásicas, el entrevistador hace uso de ciertas estrategias discursivas generales. Entre las más salientes encontramos: expresar una opinión por el otro, crear escenarios, emplear otras voces, emplear autosarcasmo y reformular y expandir de manera interesada y/o humorística intervenciones del interlocutor.

\section{EXPRESIÓN DE UNA OPINIÓN POR EL OTRO}

En numerosas instancias el entrevistador se permite afirmar algo sobre los sentimientos, opiniones o pensamientos del entrevistado, datos que solamente este último conoce.

Ejemplo 14

JG: ¿Fue hippie?

Eo: Casi.

JG: Tenía pelo largo, barba...

Eo. Si, pero no era hippie porque estaba asociado a la militancia: nosotros cuestionábamos la filosofía hippie, que más que nada era un fenómeno de la sociedad norteamericana (...) Después se extendió por toda Europa además del cambio de costumbres culturales, amor libre...

JG: Eso era lo que más le gustaba. 
Eo: Sí por supuesto eso era interesante.

[IV 55 / 57]

El efecto que produce este recurso es que el entrevistador parece ser una especie de ser omnisciente que puede ver más allá de los dichos del entrevistado y saber cómo piensa o conocer sus deseos. Este recurso le permite focalizar sobre algún aspecto en particular de lo dicho por el entrevistado, generar humor y, en ocasiones, dar a la entrevista un nuevo rumbo discursivo.

\section{Ejemplo 15}

JG: De uno a diez, ¿qué calificación te pondrías en ese rubro (como amante)?

Eo: (piensa) Ocho.

JG: Fue así: pensaste cuanto creías que tenías, y después cuanto será que tengo que decir para quedar bien, no quedar ni como fanfarrón ni tirarme abajo.

Eo: Quería decir diez, debo decir siete, dije ocho. (Risas)

También en este caso el entrevistador pretende adivinar el juego mental por medio del cual el entrevistado arriba a su respuesta. En la mayoría de los casos el entrevistado confirma que lo que ha adivinado el entrevistador es cierto.

\section{ESCENIFICACIONES Y EMPLEO DE OTRAS VOCES}

En ocasiones el entrevistador construye un escenario y crea discursos ficticios que podrían pronunciar otros personajes, que suelen ser, por ejemplo, el padre o la madre del entrevistado, un amigo, o el entrevistado mismo. Esto normalmente se marca con comillas en la impresión. 
Ejemplo 16

JG: ¿A que jugabas (cuando eras chico)?

Eo: Tenía la obsesión de ver lo que había adentro de las cosas Desarmaba cuanto equipo de música, radio, enchufe había.

JG: "El nene va a ser ingeniero"

Eo: Iba a ser ingeniero.

[VII 38 / 39]

El entrevistador se posiciona como un padre que contempla a su hijo pequeño y hace predicciones sobre su futuro en base a una aparente habilidad que el niño manifiesta.

\section{Ejemplo 17}

JG: ¿Y te hacían maldades?

Eo: No. Yo era muy cocorita. Es más, a veces yo hacía maldades. Inventaba que era mi cumpleaños, para que los chicos trajeran regalos.

JG: Tenías dos o tres por año.

Eo: Hasta que mi mamá se avivó que yo llegaba con regalos.”....¿Pero de donde sacaste este regalo?"

JG : "Un señor me los regaló."

Eo: Yo ya de chiquitita sabía dónde y a quién pedir.

$[X X I 3 / 5]$

El entrevistador remeda la pretendida inocencia de una joven que aparenta no saber la procedencia de sus regalos. Al mismo tiempo parecería querer evocar el escenario en que una joven recibe regalos de un desconocido a cambio de favores sexuales.

\section{Ejemplo 18}

Eo : [...] No me bancaba que no vieran todo lo bueno y lo maravilloso que era. JG: "No soy sólo una cara bonita" 
Eo: Exacto (Risas)

[XXIII $19 / 20]$

En este caso el entrevistador utiliza una frase estereotipada que podría ser dicha por cualquier persona del ambiente artístico que quisiera convencer al público de que su fama no se debe sólo a su apariencia física, sino a su talento artístico.

Ejemplo 19

Eo: [....] Yo me crié en Excursionistas. Mi abuelo era el utilero de Excursionistas, y tengo recuerdos muy hermosos del carnaval.

JG: "Tengo un recuerdo muy hermoso de toda la primera de Excursionistas".

Eo: Nooo. Yo ahí era chica. Hasta los trece, catorce.

[XXXVII 42 / 43]

La entrevistada está hablando de su niñez y sus recuerdos con respecto a un club de fútbol. El entrevistador habla como si fuera la entrevistada y en su característico juego del doble sentido, le hace decir que tiene un recuerdo hermoso de todos los jugadores de la primera división. El double entendre consiste en interpretar esta emisión en el sentido de que la entrevistada ha tenido relaciones sexuales con todos los jugadores. Esto se evidencia en la respuesta de la entrevistada, quien asegura que era chica en el momento del que se habla, es decir, demasiado pequeña para relacionarse con los hombres en la manera sugerida por el entrevistador.

La creación de escenarios es un recurso que permite al entrevistador construir contextos diferentes dentro de la entrevista. Estos escenarios no cumplen funciones ilustrativas o explicativas, como en el caso descrito por Gülich (2003), sino que permiten al entrevistador ampliar el rango de su repertorio de estrategias destinadas a producir efectos humorísticos. Esos contextos pueden ser fácilmente reconocidos e interpretados por los 
entrevistados y los lectores que pertenecen a la misma comunidad lingüística del entrevistador.

Asimismo, el uso del estilo directo estableciendo un juego de roles le permite al entrevistador, por un lado, distanciarse de sus dichos y hablar por boca de otro, y al mismo tiempo, traer a la escena la experiencia de lo vívido, lo inmediato, recreando un contexto familiar. Este recurso le cabe perfectamente a su rol de performer y le permite establecer un juego de voces, en el cual muchas veces participa el entrevistado mismo utilizando el mismo recurso. Este recurso está combinado en varios casos con el uso de frases estereotipadas que típicamente son empleadas por determinadas personas en contextos similares.

\section{Autosarcasmo} bromas:

Con frecuencia el entrevistador se erige en blanco de sus propias

\section{Ejemplo 20}

Eo: [....] Tenía complejo de gordo, de petiso...

JG: A mi me parece que tenés una altura normal. Hasta te veo un poco alto.

Eo: Se ve que de chico, mi falta de poder enfrentar las cosas normalmente hacía que yo me sintiera petiso, gordo, disminuido [.....]

[VII $9 / 10]$

El entrevistador hace referencia en numerosas ocasiones a su escasa altura. En el ejemplo 20, la perspectiva del entrevistador, quien es notoriamente bajo, mitiga el hecho de que el entrevistado se hubiera visto a sí mismo como muy bajo.

Al reírse de sí mismo el entrevistador se ubica en el mismo plano que el entrevistado. Parece querer decir "Yo hago bromas a costa tuya pero también 
puedo hacerme bromas a mi mismo." La consecuencia discursiva es solidaridad con el entrevistado y refuerzo del rapport.

\section{REFORMULACIONES Y EXPANSIONES DE LOS DICHOS DEL OTRO}

Con frecuencia el entrevistador toma parte de los dichos del entrevistado y los reformula o los expande produciendo un vuelco interpretativo con efecto humorístico.

\section{Ejemplo 21}

JG: Imagino que entrar al mundo del espectáculo te cambio la vida.

Eo: Fue un placer enorme [...] escuché conversaciones maravillosas que me fueron formando; nunca nadie se aprovechó de mi; fui tratada con mucho amor.

JG: Solo se aprovecharon de vos cuando quisiste.

Eo. Nada más.

"Aprovecharse" de alguien significa sacar ventaja sin que la persona se dé cuenta de que está siendo engañada. La expresión también posee una connotación sexual. El entrevistador toma parte de lo dicho por la entrevistada y lo expande produciendo un efecto humorístico por medio de una aparente contradicción: la entrevistada permitió que se aprovecharan de ella sólo cuando ella quiso. Si esto fue así, entonces la entrevistada no fue engañada sino que sabía lo que estaba ocurriendo. Curiosamente, la entrevistada admite que fue así. De esta forma, entra en el juego de su interlocutor aceptando la broma.

\section{Ejemplo 22}

JG: ¿Cuántos temas tuyos se estrenaron en Grandes Valores (del Tango)?

Eo: No muchos porque no tengo demasiados tangos, aunque Piazolla 
me acusaba de usar a Grandes Valores para poner mis temas, cosa que no era cierta.

JG: ¿Los cantores te podían decir: "No, Soldán ${ }^{28}$, ése no lo canto"?

Eo: Jamás le pedí a alguien que cantara un tema mío, nunca.

JG: Los echabas sin pedirles nada.

Eo: No, yo no tenía poder de decisión, y tampoco me interesaba tenerlo.

[II 7/9]

Luego de hablar sobre varios programas que condujo el entrevistado, Silvio Soldán a lo largo de su carrera, Guinzburg pregunta cuántos de los temas compuestos por el entrevistado fueron presentados en el programa Grandes Valores del Tango. El entrevistador pregunta a continuación si los cantantes que se presentaban en el programa tenían la opción de rehusarse a cantar los temas compuestos por Sóldan. El entrevistado contesta enfáticamente que nunca pidió a nadie que cantara un tema suyo. El entrevistador sugiere entonces que Soldán directamente echaba a los cantantes sin pedirles nada. Esta broma representa una amenaza a la imagen del entrevistado, ya que lo hace aparecer como una persona despótica que ejerce su autoridad desde su rol de conductor. El entrevistado resguarda su imagen construyendo otra como una persona a la que no le interesa poseer poder.

\subsubsection{Recursos lingüísticos}

En esta sección comentaremos sobre los usos especiales del lenguaje que emplea el entrevistador en su accionar discursivo.

${ }^{28}$ Silvio Soldán es un conductor de programas de televisión. 


\section{Polisemia}

Se caracteriza a la polisemia ${ }^{29}$ como el fenómeno por el cual una misma forma lingüística posee más de un significado. En nuestros ejemplos los diferentes sentidos de una palabra son evocados para producir un efecto humorístico.

\section{Ejemplo 23}

JG: Ibas al Champagnat ${ }^{30}$. Ahí debía haber paquetes en serio.

Eo. Ahí había paquetes paquetes. Paquetes importantes.

JG: Casi encomiendas.

[IX $9 / 10]$

En este ejemplo el entrevistador juega con el significado ordinario de "paquete" y su uso local coloquial como persona "elegante", perteneciente a la clase acomodada. En su respuesta, el entrevistado afirma que efectivamente en el colegio al que concurría había alumnos de clase acomodada (a los que nombra como "paquetes paquetes" y "paquetes importantes" en concordancia con los dichos del entrevistador "paquetes en serio"); el entrevistador agrega entonces la frase "casi encomiendas", evocando el sentido ordinario de "paquete" según el cual "encomienda" sería un paquete más grande y más valioso, y a la vez dando a entender que eran personas realmente importantes. A pesar de que la palabra "paquete" en su sentido coloquial no está relacionada con la palabra "encomienda", el entrevistador establece esta asociación no habitual que puede ser interpretada fácilmente por el interlocutor, ya que usa el término en el contexto que ha sido creado para el significado coloquial de "paquete". El entrevistador frecuentemente despliega su ingenio a través de asociaciones de este tipo.

\footnotetext{
${ }^{29}$ La polisemia es el caso en el cual una pieza léxica tiene más de una definición. Lo opuesto es la sinonimia (Leech, 1977:117)

${ }^{30}$ Colegio privado de Buenos Aires, considerado selecto.
} 
En el siguiente ejemplo el entrevistador juega con el doble sentido de la palabra "marrón" en una secuencia por cierto subida de tono, que es típica de la faceta transgresora de su identidad.

\section{Ejemplo 24}

Eo: Yo debuté con una profesional que me costó tres marrones.

JG: Es una confesión increíble.

Eo: No, (Risas) yo hablo de tres billetes marrones. Si me hubiera costado un marrón, ya, pero tres marrones hubiera sido demasiado caro.

[XXIII 23 / 24]

En este ejemplo el entrevistado habla de su primera experiencia sexual con una prostituta a la que le pagó por sus servicios tres billetes de 10 pesos ("tres marrones" en el uso local porteño). El entrevistador parece ingenuamente sorprendido ante esta confesión. Como en realidad lo dicho por el entrevistado no tiene nada de sorprendente o increíble, se produce una implicatura conversacional (Grice, 1975) en la cual el entrevistado infiere que el entrevistador está implicando algo más: pretende haber entendido la palabra "marrón" en su sentido vulgar local ${ }^{31}$. El entrevistado se ríe y explicita que el sólo hablaba de dinero.

En el ejemplo que transcribimos a continuación, el entrevistador se toma el atrevimiento de sugerir que su entrevistado, un conocido político, ha hecho fortuna con la droga:

Ejemplo 25

JG: ¿El dinero lo hizo con la yerba?

Eo: En un $90 \%$

JG: ¿Y es de fumar yerba?

Eo: No, aclaremos que estoy hablando de yerba mate.

31 “Entregar el marrón": tener sexo anal. 
JG: ¡Ah, con la yerba mate!

Eo: Obviamente.

[XVII 44/46]

El entrevistador juega con la polisemia de "yerba" como lo que se utiliza para preparar mate y como "marihuana". El entrevistado dice que su fortuna fue hecha en un $90 \%$ con la yerba (mate). Cuando el entrevistador le pregunta si fuma yerba, evocando el segundo significado, se produce un momentáneo vuelco interpretativo, en el que el entrevistador aparece por un instante como confesando haber hecho su fortuna con la droga. El entrevistado se ve obligado a aclarar de que yerba se trata y el entrevistador pretende entonces haber entendido recién en ese momento, como si hubiera habido una confusión acerca del término causada por el entrevistado.

\section{JUEGOS DE PALABRAS}

El entrevistador juega con alusiones a otros ámbitos a partir de sintagmas prototípicos ligeramente modificados.

Ejemplo 26

Eo: Llevo cuarenta y un años de casado, cinco años de novio. Es decir, son cuarenta y seis años junto a la misma mujer.

JG: Socio vitalicio.

Eo: Más que eso....

[XIII 32/33]

El entrevistado Macaya Márquez, comentarista de fútbol, comenta sobre la cantidad de años que lleva casado con la misma mujer. El entrevistador hábilmente utiliza una frase que evoca el contexto en el cual a un socio de un club que ha permanecido en la institución por muchos años se lo nombra "socio vitalicio", estableciendo así una relación entre la pertenencia prolongada a un club y un matrimonio de larga data. 
Ejemplo 27

Eo: ...yo no tenía poder de decisión, y tampoco me interesaba tenerlo. Podía sugerir traer a alguien (para cantar en el programa) pero sacar a alguien, no.

JG: El tuyo es un caso de obediencia debida televisiva.

Eo: Efectivamente. Algunos había que traerlos por compromiso. En la época militar te los mandaban los generales y coroneles........

[II 9/10]

En este caso el entrevistado es Silvio Soldán, quien está comentando sobre su poder de decisión para invitar a determinados artistas a cantar en un programa que él solía conducir. El entrevistador, haciendo gala de su creatividad, produce un juego de palabras (señalado en negrita) aludiendo a una famosa ley ${ }^{32}$ promulgada durante la vuelta a la democracia, que permitió a algunos militares de menor rango, juzgados por delitos de violación a los derechos humanos, ampararse en la obediencia debida hacia sus superiores para ser eximidos de responsabilidad y lograr una reducción de la pena. En el caso de Soldán, éste debía también acatar órdenes de sus superiores: los dueños del canal de televisión o los productores del programa.

\section{EMPLEO DE COLOQUIALISMOS, VULGARISMOS Y VOCES LUNFARDAS}

En cuanto al léxico, se encontraron en el corpus numerosas ocurrencias de vocablos coloquiales y algunos términos vulgares, así como también algunas voces provenientes del lunfardo.

El Diccionario del Habla de los Argentinos (2003) señala dentro de las marcas de valoración del uso social (marcas diastráticas y diafásicas): el nivel normal, que no lleva marcación y que corresponde al nivel de trato formal

\footnotetext{
${ }^{32}$ La ley de Obediencia Debida fue sancionada en 1987.
} 
urbano; el coloquial, de uso cotidiano y el nivel vulgar, de uso desaconsejable.

El lunfardo, por otra parte, nace entre los años 1870 y 1920 o 1925, como lenguaje de la cárcel y del arrabal porteño, y de los centros de fusión lingüística, representada en los conventillos de inmigrantes. Posteriormente se produce su expansión geográfica, llegando a países vecinos, y sociocultural. Algunos lunfardismos han sido adoptados como argentinismos (tal es el caso de las voces "mina" y "laburo", entre muchos otros) y pueden oírse hoy en día en el habla de personas de clase media y alta.

En nuestro corpus, tanto el entrevistador como el entrevistado emplean en ocasiones voces de los registros mencionados anteriormente. La mayoría de las voces marcadas corresponde a usos coloquiales ("pibe", "curda", "milico", "chinchudo"), un pequeño grupo al nivel vulgar ("joda", "curro") y otro pequeño grupo al lunfardo ("mina", "laburo") (cf. tabla de datos III). Nuestro interés está centrado en el uso de voces de los distintos niveles que emplea el entrevistador como herramienta para la constitución de su identidad. Transcribimos algunos ejemplos que contienen los vocablos en uso:

\section{Ejemplo 28}

JG: ¿Se tiró algún lance ${ }^{33}$ (con vos) Luis Miguel?

Eo: No, ¿Sabés que no?

[XXXIX 49]

\footnotetext{
${ }^{33}$ En el uso coloquial, "tirarse un lance" significa intentar conseguir algo aunque sean difíciles o dudosas las posibilidades.
} 
Ejemplo 29

JG: ¿Porque marcaba muy fuerte los límites o porque te fajaba ${ }^{34}$ dos o tres veces por día?

Eo: Era un padre castigador.

[XXVI 2]

Ejemplo 30

JG: ¿Sos adicto al laburo ${ }^{35}$ ?

Eo: Terriblemente.

En el plano afectivo, el efecto del uso de voces pertenecientes a diferentes registros es que se establece cercanía con el interlocutor y el lector. Ubica a los tres participantes del triángulo discursivo en un plano más familiar, más íntimo al compartir un código común, no abierto a extraños. El uso de voces lunfardas y coloquiales convoca una audiencia competente, capaz de decodificar los vocablos.

Según Bauman, el arte verbal se desvía de las normas que como miembros de la sociedad hemos aprendido a esperar del medio empleado y el performer hace uso maximizado de la lengua de modo que atrae la atención (Bauman, 2001:30). En nuestro caso, el performer transgrede las normas impuestas para el género entrevista, empujando los límites de lo permitido o socialmente aceptable, y utiliza ciertos recursos y una determinada selección léxica en forma recurrente, que no son habituales en las entrevistas escritas, como parte de su repertorio identitario. Podemos decir, además, que en su totalidad el tipo de humor utilizado convoca una audiencia competente que es capaz de entenderlo y disfrutarlo, generalmente los miembros de la comunidad

${ }^{34}$ En el uso vulgar, " fajar" significa golpear o castigar
35 "Laburo" es una voz lunfarda que significa trabajo. 
lingüística a la que pertenecen los participantes, quienes conocen los códigos y son capaces de decodificar sus significados.

Como hemos visto, ya sea en el caso de la alternancia de marcos, en el empleo de recursos retóricos o discursivos el entrevistador necesita de su interlocutor para llevar a cabo su trabajo discursivo identitario. Sin la colaboración de éste no podría producirse un verdadero proceso interactivo de construcción de la identidad. Por otra parte, en el mismo proceso en que emerge la identidad del entrevistador, se revela parte de la identidad del entrevistado quien en la mayoría de los casos se muestra como capaz de decodificar el tipo de humor y de replicarlo en ocasiones.

Los recursos que analizamos en esta sección son empleados por el entrevistador dentro de los marcos de humor, pero rara vez tienen estos autonomía para producir un efecto gracioso o humorístico de por sí. El humor depende de un cúmulo de factores que tienen que ver en parte con el co-texto y muchas veces con el contexto cultural, con presuposiciones compartidas y juegos del lenguaje que se apoyan en otros elementos que no son solamente los lingüísticos. 


\section{LA IDENTIDAD DEL ENTREVISTADO}

\section{Procesos interactivos de categorización}

La identidad del entrevistado se construye a través de categorías en las que se incluye o es incluido por el entrevistador, en un proceso interactivo que puede extenderse a lo largo de dos o más turnos. Los procesos de categorización se desatan, por ejemplo, ante una pregunta del entrevistador, cuyo rol consiste en lograr obtener información del entrevistado para el público lector.

Ejemplo 31

JG : Solita ${ }^{36}$, ¿vos quién sos?

Eo : Soy una laburanta, una madre que ama profundamente a sus hijos, soy una buena mina......

En este contexto la pregunta no es entendida como un pedido de identificación (el entrevistador sabe quién es su interlocutor; es más, se dirige a la entrevistada por su nombre), sino más bien como una invitación a la autocategorización, que es precisamente el foco de la entrevista. Al dar su respuesta, la entrevistada se inscribe en tres categorías("laburanta", "madre" y "buena mina") con las que conforma una determinada identidad para presentarse ante el público. En este caso, la entrevistada desea dar la imagen de una persona común, que se gana la vida trabajando con esfuerzo ("soy una laburanta"), y cuyos intereses personales están alejados del mundo frívolo de la actuación y centrados en su familia ("una madre que...."). El uso de las voces lunfardas "mina" y "laburanta" no es casual, sino que cumple el propósito de reforzar la voluntad del hablante de identificarse con la categoría "persona común".

${ }^{36}$ La entrevistada es la actriz Soledad Silveyra 
En las entrevistas se abordan diferentes temas relacionados con la vida del entrevistado. Son recurrentes en casi todas las entrevistas ciertas áreas temáticas o tópicos tales como infancia, familia, clase social de pertenencia, trabajo, relación de pareja, religión. En muchas ocasiones, dentro de estas secuencias temáticas, el entrevistador utiliza su turno para hacer preguntas, orientadas a inscribir al entrevistado en determinadas categorías. La adscripción a una cierta categoría desata determinadas inferencias sobre el entrevistado. El público lector reconstruye la identidad del entrevistado a través de estas categorías y las inferencias ligadas a ellas.

\subsection{Categorizaciones directas e indirectas}

El entrevistador realiza su trabajo discursivo de dos maneras: a) en forma directa, que constriñe la respuesta, utilizando en la pregunta la fórmula ¿Sos/ eras (un) $X$ ? o ¿Sos $X$ o $Y$ ? y variantes de las mismas (ver ejemplos 32-36); b) formulando una pregunta más amplia, por ejemplo: “¿Vos quién sos?”, “¿Cómo eras de chico?” o “¿Cómo sos como padre?”.

$\begin{array}{lll}\text { Ejemplo } 32 & \text { ¿Sos una máquina sexual? } & \text { [II 43] } \\ \text { Ejemplo } 33 & \text { ¿Sos mamero o papero? } & \text { [II 50] } \\ \text { Ejemplo } 34 & \text { ¿Es guardabosque? } & \text { [IV 12] } \\ \text { Ejemplo } 35 & \text { ¿Eras de ciudad o de campo? } & {[\text { XXIX 4] }} \\ \text { Ejemplo } 36 & \text { Usted en su juventud ¿era un nerd? } & \text { [VI 56] }\end{array}$

En estos casos el entrevistado se ve forzado a definirse, inscribiéndose en la categoría o rechazándola, o haciendo una elección entre las alternativas propuestas. Además, normalmente realiza operaciones de precisión o ampliación, como se muestra en los ejemplos siguientes:

\section{Ejemplo 37}

JG: ¿Sos gasolero? 
Eo: Sí, pero porque soy poco entusiasta, y no soy consumista, para nada.

El entrevistador pregunta sobre los hábitos de compra del entrevistado, utilizando el término coloquial "gasolero" ("que gasta poco"). El entrevistado confirma, inscribiéndose en la mencionada categoría y precisándola: explica las razones de su aceptación, mencionando que no es consumista e invocando de esta manera el otro término del par relacionado (cf. Sacks (1992) Standardized Relational Pair ${ }^{37}$ gasolero/consumista.

\section{Ejemplo 38}

J.G: Virginia, ${ }^{38}$ me contaron que vos sos la intelectual del grupo.

Eo : Soy la que siempre lleva un libro adentro de la cartera y soy muy racional. Pero no por eso soy la intelectual del grupo.

La entrevistada se resiste a ser catalogada como "la intelectual del grupo". Sin embargo, se autoasigna atributos típicamente asociados a la categoría de intelectual, como "llevar siempre un libro" y "ser racional". Por medio de esta aparente contradicción la entrevistada rechaza su grado de representatividad en el grupo con respecto a la categoría intelectual, pero al mismo tiempo menciona las actividades o atributos típicos de la categoría que sí manifiesta tener. La entrevistada trata de evitar el encasillamiento por parte del entrevistador delineando la categoría de intelectual a través de los ALC ${ }^{39}$ que ella menciona.

\footnotetext{
${ }^{37}$ Standardized Relational Pair es un tipo particular de dispositivo de categorización en el cual una categoría es empleada en conjunción con otra que naturalmente "va con ella "ej. doctor /paciente. Cf. Hester \& Eglin (1997:4).

${ }^{38}$ Integrante del grupo popular Bandana

${ }^{39}$ Actividades o atributos ligados a la categoría
} 
Ejemplo 39

J.G: ¿Eras hijo modelo o tiro al aire?

Eo: Era una mezcla casi perfecta, no era ni el buen alumno, ni me dejaban llevar materias.....

El entrevistado opta por ubicarse en un término medio entre el par relacionado hijo modelo/ tiro al aire, nombrando Actividades Ligadas a las dos categorías "ser buen alumno" y "llevarse materias" respectivamente.

En otros casos, al ser las preguntas más abiertas, se permite al entrevistado una mayor libertad:

Ejemplo 40

J.G: ¿Como eras de chico?

Eo: Más o menos como ahora, porque no renuncio a la niñez.

[VIII 12]

\subsection{Figuras estereotípicas}

En ocasiones, la adscripción a una categoría se produce a través de un trabajo discursivo indirecto, por medio del cual se invoca una figura estereotípica que posee una característica saliente particular:

\section{Ejemplo 41}

Eo: ...y yo, que no quiero asumir mis cuarenta y cuatro.....

JG: ¿Tenés una cosa de Peter Pan? ¿Te sale el adolescente?

Eo: Yo, que vivo haciéndome el adolescente, como bien decís vos.... 
Este recurso también es replicado por algunos de los entrevistados para caracterizarse a sí mismo:

Ejemplo 42

JG: En algunos reportajes que les hicieron destacan que venís de un hogar muy humilde.

Eo: Sí, pero tampoco soy Trapito (..) Para ser pobre, no hace falta vivir debajo de una sábana.

O para caracterizar a un tercero que también está siendo entrevistado, en el caso de la entrevista grupal (entrevista $\mathrm{XL}$ ):

Ejemplo 43

JG: ¿Qué le envidian a la otra (integrante del grupo)?

$($...........................................)

Eo: Yo admiro la tranquilidad de Ivonne, la Wan Chan Kein de Bandana $^{40}$.

La sola mención de estos personajes, que pertenecen al bagaje de conocimiento compartido por los hablantes, evoca las características salientes por las que son conocidos. ${ }^{41}$ En los ejemplos que mostramos, los interlocutores, además de nombrar a los personajes, explicitan la cualidad que los define y por la cual son conocidos por los hablantes: Peter Pan, el personaje del folklore infantil, es el niño que nunca crece (Ejemplo 41: Peter Pan / adolescente) ; Trapito, personaje del cine infantil argentino, es un pobre espantapájaros vestido con harapos (Ejemplo 42: Trapito / pobre); ); Wan Chan Kein, personaje televisivo, es un hombre que, guiado por la filosofía oriental,

\footnotetext{
${ }^{40}$ Grupo de música popular.

${ }^{41}$ Cf. el tratamiento de la categoría "Fagin" en Antaki (1998)
} 
puede controlar su mente y su cuerpo de tal manera que permanece inmutable ante cualquier situación (Ejemplo 43: Wan Chan Kein / tranquilidad)

\subsection{Rasgos estereotipados}

Resultan interesantes otros casos de categorización, en los cuales el entrevistador exige explicación ante una aparente contradicción en la apariencia del entrevistado. En los dos ejemplos que presentamos a continuación el entrevistador inscribe al entrevistado en categorías de raza (armenio / indígena), y obliga al entrevistado a ratificar o refutar esta apreciación y a explicar el presunto desajuste en su apariencia.

Ejemplo 44

J.G: Sos rubio, tenés ojos claros pero tu apellido es armenio.

Eo: Mi abuelo nació en Armenia y (.....) se vino a la Argentina, (.......) conoció a mi abuela y se casaron.

JG: ¿Para que salgas con ojos claros?

Eo: Mi abuela es descendiente de italianos, de ella saco los ojos claros.

[XXXIV 84/85]

El entrevistado se ve forzado a explicar porque es rubio y de ojos claros si, según su apellido, y en opinión del entrevistador, debería ser de tez y cabellos oscuros (la categoría "armenio" desencadena ser "oscuro"). Su explicación intenta sugerir que hubo una mezcla de razas, pero no resulta del todo clara y esto da pie al entrevistador para hacer una broma. El entrevistado finalmente logra aclarar el aparente desajuste entre la procedencia de su apellido y su apariencia física.

Ejemplo 45

JG: ¿Cuál es tu verdadero nombre? 


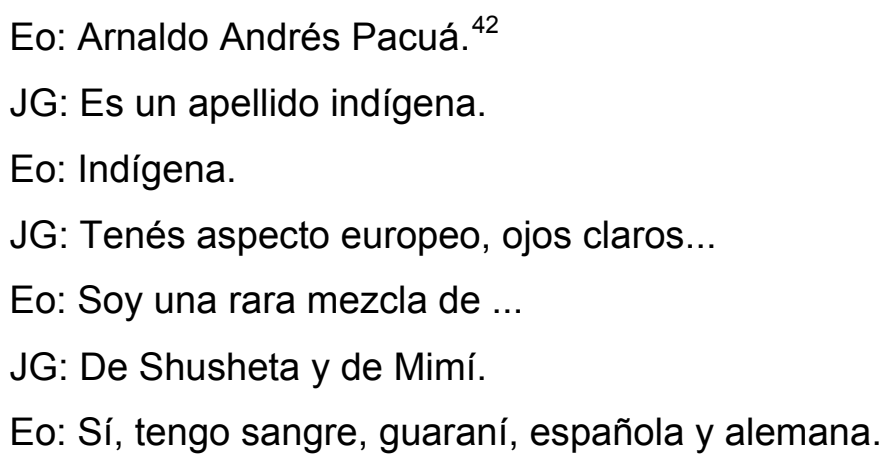

$[\mathrm{XXXIII} \mathrm{I/4]}$

Una vez más, el entrevistador sugiere que según el apellido del entrevistado sus rasgos deberían ser aindiados, no europeos. El entrevistado explica esto diciendo que es el producto de una mezcla. El entrevistador aprovecha una vacilación del entrevistado para tomar el turno y completar la contribución del otro en forma humorística, citando la letra de un tango. A continuación, el entrevistado logra completar su turno mencionando su origen mixto.

\subsection{Actividades ligadas a las categorías}

En otros casos la categorización del entrevistado se produce a través de la adscripción a categorías por medio de Actividades Ligadas a la Categoría (ALC), es decir aquellas que se espera que los representantes de las categorías lleven a cabo correctamente. En el caso que sigue la pertenencia a la categoría "gitano" desencadena una actividad considerada típica de su categoría en nuestro medio:

\section{Ejemplo 46}

JG: Otra vez estás haciendo de gitano.

Eo: Sí, por tercera vez.

JG: ¿Será que te ven como un gitano y por eso te eligen con tanta asiduidad?

Eo: (Risas) Creo que es una casualidad.

JG: ¿Sos de vender autos usados?

${ }^{42}$ El entrevistado es el actor paraguayo Arnaldo André. 
Eo: (Risas) Mis autos usados son bastante bien solicitados, pero no.

[XXXIII 65 / 67]

El entrevistador hace referencia al hecho de que el actor ha representado personajes de gitano en varias oportunidades. Sugiere que, tal vez por su apariencia, los productores lo ven como a un gitano, y por eso lo eligen. El entrevistado se ríe y rechaza esta posibilidad. A continuación, J. Guinzburg hace un segundo intento de categorización y pregunta al actor si vende autos usados (recordemos que en nuestro medio el gitano estereotípico vende autos usados). El actor vuelve a reír ante la inesperada pregunta y dice que no se dedica a eso, cerrando el marco de humor. Lo que resulta humorístico es la sugerencia por parte del entrevistador de que la actividad de vender autos en la vida real pueda haber asemejado al actor a un gitano, al menos a los ojos de los productores de televisión, y en consecuencia estos le hayan asignado el papel de gitano en distintos programas de la televisión.

En el caso que sigue las categorías evocadas se relacionan con el género:

\section{Ejemplo 47}

JG: ¿En que se notaba (que eras homosexual/ bisexual) ${ }^{43}$ ¿Tus compañeros de colegio jugaban al fútbol y vos querías jugar con muñecas?

Eo: No, en absoluto. Yo jugaba al fútbol con ellos.

JG: Eso sí, le ponías pelucas a la pelota y la pintabas con rouge.

Eo: No de veras, yo no era un niño afeminado y aún ahora creo que tampoco lo soy.

JG: No, ahora tampoco.

Eo: No me ponía ropas de mujer y era muy aficionado al fútbol (....), jugaba al fútbol con todos mis compañeros. En eso era muy normal.

[XXXVIII $23 / 25]$

\footnotetext{
${ }^{43}$ El entrevistado es el periodista y escritor peruano Jaime Bayly.
} 
Aquí se alude a las categorías "niño" / "niña" y a las actividades asociadas de jugar al fútbol y jugar con muñecas que típicamente en la cultura occidental tradicional se les suele atribuir respectivamente. El entrevistador busca categorizar al entrevistado mediante ALC como inclinado a realizar actividades que prefieren las niñas. Ante el rechazo del entrevistado, el entrevistador logra una combinación humorística de las dos actividades, que cabría al bisexual ("ponerle pelucas a la pelota" y "pintarla con rouge"). El entrevistado vuelve a rechazar esto y afirma no ser ni haber sido "afeminado". La identidad con la que quiere presentarse es la del "bisexual", pero no afeminado. Al cierre de este marco de humor, el entrevistado quiere dar una imagen de persona "normal", invocando ALC como "vestir ropa de mujer" para las mujeres y "jugar al fútbol" para los varones, y sostiene que él se dedicaba sólo a actividades atribuibles a los varones como esta última y que en eso "era muy normal". Resulta notable como mediante este último comentario indirectamente adscribe al bisexual en la categoría de "no-normal".

En los ejemplos que hemos visto, la categorización es coproducida. No es suficiente que uno de los participantes invoque la categoría o incluya al otro en ella. El entrevistado reacciona a la propuesta de categorización de distintos modos y, ya sea que la acepte o rechace, produce frecuentemente actividades reformulativas expansivas (cf. Gülich y Kotschi, 1995) que precisan, corrigen o amplían los contenidos evocados por las etiquetas. Esto permite que la secuencia pueda completarse y se produzca un verdadero proceso de categorización interactiva.

Como hemos visto en el capítulo 4, las categorizaciones no son un mecanismo relevante para construir la identidad del entrevistador. El entrevistador construye su identidad discursiva principalmente a través de otros procesos interactivos ya descritos, como la alternancia de marcos de humor y marcos serios. El foco de interés de la entrevista es el entrevistado y es su identidad la que debe ser revelada al público. Esto se logra a través de los procesos de categorización iniciados generalmente por el entrevistador. 
Sin embargo, podemos afirmar que, si bien la identidad del entrevistador no se construye básicamente a través de procesos de categorización, en el mismo proceso iniciado por el entrevistador para categorizar al otro se va delineando su propia identidad discursiva. Como pudimos apreciar en algunos de los ejemplos ya citados, el entrevistador utiliza ítems de vocabulario corriente y popular para caracterizar al entrevistado, como por ejemplo: "nerd" [VI 56] o "gasolero" [III 53]. Estos usos particulares lo hacen aparecer como conocedor del lenguaje popular y esto está de acuerdo con la identidad discursiva que busca construir para sí mismo. En el ejemplo 45 le sugiere al entrevistado que es una mezcla de "Shusheta y de Mimi" [XXXIII 1/4], lo cual lo presenta como conocedor de la música popular porteña. En el ejemplo 47 su visión estereotipada de los géneros (los niños juegan a la pelota y las niñas con muñecas) revela una posición tradicional sobre el tema. 


\section{LA IDENTIDAD DE LOS INTERLOCUTORES}

\subsection{Fórmulas de tratamiento}

Las fórmulas de tratamiento son aquellas empleadas por los hablantes para dirigirse a su interlocutor. Existen formas nominales (por ejemplo, Señor, pibe, doctor, que son de uso corriente en el español rioplatense) y formas pronominales (pronombres personales como tú/vos o usted), por medio de las cuales los hablantes indican distancia relativa con respecto a su interlocutor.

Con respecto a las fórmulas pronominales de tratamiento, el español rioplatense presenta un paradigma dual, conformado por la forma de respeto usted y por la forma vos, que es menos formal. Ambas fórmulas son seleccionadas oportunamente por los hablantes, según entren en juego distintas variables como edad, clase social, distancia psicológica, etc. El voseo expresa familiaridad, informalidad, solidaridad (cuando el trato es recíproco, por ejemplo, entre pares o interclase) y acercamiento psicológico o afectivo. Si el vos responde a un trato no recíproco, puede significar menor autoridad del que recibe ese tratamiento. Por medio del usted no recíproco se expresa poder y formalidad. Se polariza el usted en el que tiene más autoridad, más jerarquía o más edad. El usted solidario (solidaridad deferente) es usado entre iguales cuando se quiere mantener distancia o cuando entran en juego diferentes variables como más edad de uno pero mayor prestigio social del otro. También puede expresar distancia psicológica o distanciamiento momentáneo (Carricaburo, 1997:9).

Hemos prestado especial atención al uso que los hablantes hacen de las fórmulas de tratamiento pronominal usted y vos en las entrevistas analizadas. Según una de nuestras tesis, ${ }^{44}$ existe una cierta relación entre el empleo de las fórmulas de tratamiento pronominal usted y vos, que habitualmente señalan mayor o menor distancia entre los participantes, y la cantidad de marcos de

${ }^{44}$ Cf. Sección 1.2, p.4 
humor existentes en una determinada entrevista, tema que analizaremos en mayor profundidad en la Sección 6.2. En la presente sección buscamos establecer la relación entre la frecuencia de uso de vos o usted con el establecimiento de cercanía o distancia y el rapport que se produce en consecuencia.

En nuestro corpus aparecen las siguientes combinaciones del paradigma local, empleadas por los participantes de la entrevista para dirigirse al otro, a saber: vos / vos (34 casos), usted / vos (4 casos) y usted / usted (2 casos) ${ }^{45}$. Podemos explicar la mayor ocurrencia del vos recíproco de la siguiente manera: para que la entrevista sea exitosa, el entrevistador debe lograr establecer un alto grado de rapport con su entrevistado. Una de las formas de lograrlo es creando un clima de intimidad y familiaridad. Esto se lleva a cabo, en parte, mediante el uso de formas de tratamiento que expresan solidaridad, familiaridad e informalidad, como es el caso del vos en el español rioplatense. Esta alta frecuencia de uso del vos en nuestro corpus coincide, además, con su progresivo empleo generalizado en diferentes contextos, en detrimento del usted en la cuenca del Plata, señalado por Carricaburo (1997: 24).

El entrevistador es quien ocupa el turno de apertura, por eso puede ser el primero en seleccionar la fórmula de tratamiento que cree apropiada para lograr sus propósitos discursivos. En la casi totalidad de las entrevistas analizadas, el entrevistador marca su elección de fórmula de tratamiento en el primer turno que ocupa. Cuando la marca no ocurre en el primer turno, aparece en la segunda contribución del entrevistador, o no más allá del par adyacente $N^{0}$ 10. Cuando, a su vez, el entrevistado co-selecciona el vos (34 casos), se establece menor distancia y un alto grado de afiliación (cf. vos recíproco, Carricaburo, 1997: 24).

Por otra parte, el entrevistador sólo utiliza el usted en 6 oportunidades para dirigirse a su entrevistado, que en todos los casos es un político local.

${ }^{45}$ Cf. Tabla de datos II en el Apéndice 
Este uso está marcado seguramente por varios factores: no hay conocimiento personal previo, es mayor la edad o el estatus del entrevistado. Sin embargo, no todos los políticos son tratados de usted (cf. entrevista XII a Rodolfo Terragno ${ }^{46}$ ), lo que nos lleva a deducir que el uso de una forma u otra no tiene que ver con la actividad del entrevistado en sí, sino mayormente con el grado de conocimiento previo entre entrevistado y entrevistador, o con una elección discursiva hecha en el momento de la entrevista, teniendo en cuenta el (mayor) estatus, personalidad o rasgos propios del interlocutor.

Un caso interesante corresponde a la entrevista $V$ a Aníbal Ibarra ${ }^{47}$, en la cual J. Guinzburg sostiene el uso del usted durante toda la entrevista, aunque hacia el final imprevistamente cambia al vos. El entrevistado sigue siendo el mismo, pero el contexto dinámico creado por los interactuantes ha variado (cf. Duranti \& Goodwin, 1992). Hacia el final existe más distensión; el entrevistador ya ha cumplido con su deber discursivo y puede relajarse en la fase final. Existe más cercanía entre los participantes, que puede hacer variar la situación de inicio, si no se conocían previamente. El cambio al vos produce acercamiento, que condice con el rapport que se ha producido.

Por otro lado, sólo dos de los entrevistados, que son políticos, utilizan el usted para dirigirse al entrevistador (entrevistas XVI y XVIII). Este hecho puede obedecer a varios factores: los entrevistados desean poner distancia; no existe conocimiento previo entre los interlocutores, o en el caso de Alfonsín ${ }^{48}$, (entrevista $\mathrm{XVI}$ ) seguramente obedece a la tendencia en personas mayores de 70 años de emplear el usted como forma de respeto para dirigirse al otro, aunque el interlocutor sea menor en edad.

Entre las 34 entrevistas en las cuales entrevistador y entrevistado se dirigen al otro utilizando el vos, existen cuatro casos en los cuales el

\footnotetext{
${ }^{46}$ Político radical.

${ }^{47}$ Político perteneciente al Frepaso, que en el momento de la entrevista se postulaba para jefe de gobierno de la ciudad de Bs. As.

${ }^{48}$ Político radical de renombre y ex-presidente.
} 
entrevistado usa el tú para dirigirse al entrevistador (entrevistas VIII, XXII, XXXVIII y XL), lo cual se debe a que son personas que provienen de otros países hispanoparlantes (España, Colombia y Perú), en los cuales rige el paradigma tuteante.

En el caso de Jaime Bayly ${ }^{49}$ (entrevista XXXVIII) es interesante el hecho de que el entrevistado alterna el uso de vos (que no corresponde a su norma) y tú (que corresponde al uso familiar de Perú) a lo largo de la entrevista. Este uso alternado puede indicar un acomodamiento discursivo convergente hacia el entrevistador, generado por un mayor deseo de acercamiento. En los ejemplos que transcribimos a continuación podemos apreciar este fenómeno (marcado en negrita) en dos instancias de la misma entrevista:

Ejemplo 48

JG: Entonces no me aconsejás que para mejorar mi inteligencia me haga gay.

Eo: No, pero si (tú) quieres mejorar tu rating, sería buenísimo que digas "Soy bisexual".

[XXXVIII 12]

Ejemplo 49

JG:.....Pero la combinación de bisexualidad con drogas, imagino que lleva al desenfreno, aunque suene moralista.

Eo: Sí, absolutamente. Vos sos tan perceptivo como mi padre.

[XXXVIII 59]

La Teoría del Acomodamiento (Communication Accommodation Theory o CAT, cf. Giles,et al., 1991) busca explicar las motivaciones y las consecuencias derivadas de las formas en que adaptamos nuestra lengua y

${ }^{49}$ Escritor y periodista peruano. 
patrones de comunicación a nuestros interlocutores. Existen numerosos contextos en los cuales los hablantes convergen hacia (o divergen de) la norma o lo que suponen es la norma de su interlocutor. Esto se ve reflejado discursivamente en distintos aspectos de su producción lingüística, prosódica y no-verbal, por ejemplo, en la elección de vocabulario, patrones de entonación o postura corporal, entre otros.

En nuestro caso podemos observar que el entrevistado (Jaime Bayly) emplea el vos, que no corresponde a su norma, en forma convergente hacia la norma del entrevistado, y lo alterna con el tú. Utiliza ambas formas para dirigirse al entrevistador, o para aquellos casos en los cuales, dentro de su propio discurso, se habla a sí mismo o generaliza utilizando la segunda persona. La Teoría del Acomodamiento nos permite explicar el porque de este fenómeno. La ocurrencia de señales de convergencia puede tener lugar cuando existe una orientación hacia el interlocutor y un deseo de agradar. La convergencia puede manifestarse de numerosas formas que pueden presentarse en forma simultánea (postura corporal, patrones de entonación, etc.). Por la naturaleza de nuestro corpus sólo pueden apreciarse algunos indicadores de convergencia tales como el uso alternado de fórmulas de tratamiento.

Por otra parte, no se encontró en nuestro corpus ningún caso en el cual el entrevistador utilice el vos como forma de tratamiento y el entrevistado seleccione el usted. Dado que el entrevistador es quien toma el turno de apertura, si este selecciona el vos, el entrevistado no selecciona el usted en ninguno de los casos, ya que esto sería interpretado como un mecanismo para establecer distancia o imponer formalidad en un contexto que anticipa justamente lo contrario.

Tampoco se ha encontrado algún caso en el que el entrevistador se dirija a su entrevistado empleando la forma pronominal usted + un título profesional como "Doctor" o "Profesor". La ausencia de estas formas nominales de tratamiento contribuye a confirmar nuestra afirmación de que el 
entrevistador busca crear rapport con su entrevistado. El uso de títulos profesionales para dirigirse al otro establecería distancia, ya que señalaría mayor estatus de la persona aludida.

La selección de determinadas formas pronominales de tratamiento forma parte del espectro de recursos disponibles para los hablantes. En el caso de la entrevista la selección de una determinada forma de tratamiento por parte del entrevistador contribuye a la constitución de su identidad. El entrevistador establece cercanía mediante el uso del vos y esto contribuye a moldear su identidad como alguien abierto y accesible. Si bien su identidad discursiva principal es la de transgresor de normas e ingenioso, construida por medio de recursos retóricos, discursivos y lingüísticos y la alternancia de marcos, la búsqueda del establecimiento de rapport con el entrevistado a través de la elección pronominal lo muestra como deseoso de lograr acercamiento. Esto es necesario para neutralizar cualquier efecto negativo que las transgresiones pudieran ocasionar. En aquellos casos en los cuales el entrevistador elige el usted para dirigirse a su entrevistado, este no marca distancia o alejamiento sino respeto.

\subsection{Alternancia de marcos y fórmulas de tratamiento.}

En nuestras tesis (sección 1.2) sostuvimos que parece existir una cierta correlación entre el grado de familiaridad o distancia entre los participantes y la frecuencia con que se presenta la alternancia de marcos. Propusimos además que las fórmulas de tratamiento que habitualmente señalan mayor o menor distancia podrían ser indicadores de ello.

Por consiguiente, en esta sección analizaremos la potencial relación entre la elección de ciertas fórmulas de tratamiento y la existencia de un mayor o menor número de marcos de humor presentes en una determinada entrevista. 
Con respecto a la alternancia de marcos, vemos que este fenómeno se da con relativa frecuencia en la mayoría de las entrevistas, ya que como dijimos, es uno de los principales recursos por medio de los cuales el entrevistador construye su identidad discursiva. La alternancia de marcos no se da en número fijo, sino que varía de entrevista en entrevista. En algunas es notoriamente bajo o casi inexistente (Entrevistas V-VI-XIII-XXV-XXIX); en otras se produce en forma frecuente a lo largo de la entrevista (Entrevistas IX - XI XXXVIII - XXXIX)

Por otro lado, las fórmulas de tratamiento pronominales que son empleadas por los participantes de la entrevista (usted, vos) indican el grado de familiaridad y / o de respeto que los hablantes manifiestan hacia el otro. En la tabla II, donde se esquematizan los datos correspondientes a las fórmulas de tratamiento, podemos contabilizar la cantidad de veces que el entrevistador se dirige a los diferentes entrevistados utilizando el usted, es decir, estableciendo +distancia +respeto: total $6 / 40$ y el número de casos de usted recíproco: 2/40. También podemos apreciar la cantidad de veces en las que el entrevistador utiliza el vos, estableciendo -distancia +familiaridad: total 34 casos.

El cruzamiento de los datos nos permite observar que en aquellas entrevistas en las cuales el número de cambio de marcos es bajo, este fenómeno se da en forma independiente del uso de usted por parte de uno o de los dos participantes. Sólo en dos de las 40 entrevistas coincide el uso del usted (indicador de mayor distancia o menor familiaridad) con un número bajo de cambio de marcos (entrevistas $\mathrm{V}$ y $\mathrm{VI}$ ). Por lo tanto, en nuestro corpus la presencia de un bajo número de marcos de humor no se correlaciona con determinada forma de tratamiento. Respecto al número de casos en los cuales se observa la relación - marcos de humor +distancia entre los participantes marcado por el uso de usted, éste resulta claramente insuficiente para extraer conclusiones definitivas y permitir corroborar este aspecto de nuestra tesis. 
Por otro lado, entre las 34 entrevistas en las cuales el uso de vos recíproco indicaría +cercanía +familiaridad, se encuentran 26 en las cuales el cambio de marcos se da en número mayor a 7, y 8 en las cuales el cambio de marcos es bajo (7 o inferior a 7 en entrevistas XIII -XXV-XXVI -XXIX -XXX). En consecuencia tampoco puede probarse totalmente que el mayor número de cambio de marcos se encuentre en relación directa con el uso de determinado pronombre.

Por lo tanto, se debería ampliar el número de textos a estudiar para convalidar la tesis de que a mayor familiaridad, marcada por el uso de la fórmula pronominal de tratamiento vos, necesariamente debe darse mayor frecuencia de marcos de humor en una determinada entrevista, y a más distancia y/o más respeto, marcado por el uso de usted, debe darse menor número de cambio de marcos. Sugerimos que existió mayor posibilidad de frecuencia de alternancia de marcos cuando, durante el desarrollo de la entrevista, se logró un mayor acercamiento entre entrevistador y entrevistado, y cuando este acercamiento fue posible debido a la negociación entre los participantes. En el contexto de la entrevista esto significó que el entrevistado permitió que el entrevistador avanzara sobre su terreno, teniendo en cuenta que el entrevistador es el participante más dominante (recordemos que controla los tópicos y el curso de la interacción). El acercamiento o la distancia también pueden negociarse y pueden estar señalados por otros elementos que no son las fórmulas de tratamiento, como por ejemplo, la risa compartida, la ratificación de secuencias de humor o también, la negativa a contestar una pregunta.

En aquellos casos en los cuales el entrevistador logró construir un número mayor de marcos de humor, con la anuencia del entrevistado, podemos afirmar que logró, en consecuencia, un mayor despliegue de su identidad discursiva ante la audiencia lectora. Por el contrario, en aquellas en las cuales la alternancia de marcos se dio en menor número, el despliegue de su identidad humorística fue menor y la entrevista se asemejó en esos casos a una entrevista convencional. 


\section{CONCLUSIONES}

Esta última sección está destinada a resumir y evaluar los resultados que se proyectan como relevantes en esta investigación y ofrecer algunas consideraciones finales.

El objetivo general de este trabajo ha sido contribuir al entendimiento de cómo las personas colaboran en la construcción de distintas identidades para sí mismos y para los demás en situaciones de habla concretas en las que se ven inmersos en su accionar diario al interactuar con otros miembros de la sociedad.

En particular, hemos focalizado sobre el proceso de co-construcción de identidades discursivas, es decir aquellas que son desplegadas por los participantes en el fluir de la interacción, en la entrevista periodística de humor. Hemos mostrado, a través del análisis de numerosos ejemplos extraídos del corpus, cómo la identidad es el resultado de un proceso discursivo de elaboración conjunta del cual son responsables los participantes del evento de habla, y cómo esa identidad es relevante local y temporalmente en su contexto de uso. En la entrevista escrita, las identidades de los interlocutores se encuentran a su vez moldeadas y orientadas hacia un tercer participante: la audiencia lectora, que generalmente no es nombrada, pero que se percibe como una presencia latente durante el desarrollo de la interacción.

El análisis de los numerosos ejemplos tomados de diferentes entrevistas ha revelado cómo el entrevistador se posiciona como performer frente al entrevistado y a la audiencia lectora, empleando el cambio de marcos como su recurso estratégico principal. Desarrollamos este tema en el capítulo 4 de la Sección Analítica. Observamos como, a lo largo de cada entrevista, el entrevistador alternó el marco de humor con el marco serio, en un juego constante que le permitió, entre otras cosas, construir una determinada identidad para sí mismo: la de transgresor, ingenioso y gracioso y al mismo 
tiempo, entretener a la audiencia, tal como se espera de su condición de performer.

Si bien se realizó un análisis cualitativo del corpus, se cuantificaron algunas variables consideradas relevantes, por ejemplo, se contabilizó el número de veces que el entrevistador alternó el marco serio con el marco humorístico en cada entrevista. Estos datos fueron volcados en la Tabla de datos I. La cantidad de marcos de humor en cada entrevista resultó ser variable (un promedio de entre 7 y 22 instancias de cambio de marcos, hasta un tope de 32). No se encontraron disparadores particulares del mecanismo de cambio de marco, ni momentos especiales dentro de la entrevista en los cuales esto ocurrió en forma regular. Deducimos que el entrevistador utilizó toda aquella oportunidad que se presentó durante cada entrevista para desplegar su ingenio y reafirmar su posición de performer. La variación en el número de marcos dependió en general de la negociación y del rapport producido entre los interlocutores durante la entrevista. Observamos que a mayor número de marcos de humor presentes en una determinada entrevista, mayor fue el despliegue de la identidad transgresora del entrevistador. Por el contrario, cuanto menor resultó ser el número de marcos de humor presentes en una entrevista, menor fue el despliegue identitario logrado por el entrevistador. En estos casos la figura del entrevistador pareció retraerse de la escena, mientras que la identidad del entrevistado se proyectó en forma agigantada. La entrevista en estos casos se asemejó a una entrevista convencional, en la cual el entrevistado es el foco de interés y el entrevistador un mero intermediario entre el entrevistado y el público.

Hemos mostrado también las distintas reacciones de los diferentes entrevistados con respecto al cambio de marco. En la mayoría de los casos, el entrevistado de turno se prestó al juego iniciado por el entrevistador, riéndose y/o continuando el marco de humor y, en numerosas ocasiones, replicando los recursos utilizados por el entrevistador. Cuando esto ocurrió los dos participantes se alinearon como interlocutores dentro del mismo evento de habla, y la marcada asimetría existente entre los roles de ambos (el de 
entrevistador y entrevistado) se equilibró momentáneamente, reforzando el rapport entre los participantes. Por el contrario, cuando el entrevistado, en forma voluntaria o involuntaria, ignoró la broma, el marco humorístico perdió parte de su fuerza discursiva para los interlocutores, pero no así para los lectores de la entrevista, quienes podrán, dependiendo de su competencia lingüístico-discursiva, recuperar el sentido de lo que ha sido ignorado.

Como dijimos anteriormente, el entrevistador alternó el marco serio con numerosos marcos humorísticos, dentro de los cuales empleó figuras clásicas como la ironía y la hipérbole, estrategias discursivas como la creación de escenarios y el empleo de otras voces, para mencionar algunos, y recursos lingüísticos particulares como el empleo de coloquialismos y voces lunfardas.. Hemos mostrado el uso particular de estos recursos que realizó el entrevistador a través de numerosos ejemplos citados en el capítulo 4. Hemos encontrado que el empleo de estos recursos resultó tener tres efectos discursivos principales. En general colaboraron en: a) la construcción de la identidad del entrevistado como ingenioso y transgresor; b) el establecimiento de rapport con el entrevistado y c) la obturación de potenciales efectos negativos producidos por las bromas que pudieran representar una amenaza para la imagen del entrevistado.

Por otro lado, observamos cómo cada entrevistado desplegó su identidad a través de procesos de auto y heterocategorización (Capítulo 5). Se analizaron principalmente las preguntas hechas por el entrevistador para lograr la categorización del entrevistado. Se encontraron preguntas de dos tipos: directas e indirectas. Las respuestas de los diferentes entrevistados buscaron en general, ratificar, ampliar o corregir las etiquetas propuestas, lo que generó en algunos casos un proceso de negociación (sección 5.1). Se focalizó además sobre la adscripción a determinadas categorías mediante la invocación de figuras estereotípicas (sección 5.2) y la alusión a características físicas del entrevistado, asociadas a determinados estereotipos raciales (sección 5.3). 
Asimismo, se analizaron casos en los cuales el entrevistador buscó caracterizar al entrevistado recurriendo a las Actividades Ligadas a la Categoría (sección 5.4). Estas actividades están estrechamente asociadas a comportamientos estereotípicos de las personas que son descriptas por medio de una determinada categoría. Se observó que, en general, y como ocurrió en el caso de las preguntas, el entrevistado ratificó, corrigió o amplió las etiquetas propuestas.

Señalamos además que, si bien los procesos de categorización sirvieron principalmente para moldear la identidad del entrevistado, estos tuvieron además la función subsidiaria de delinear la identidad del entrevistador. Al proponer determinadas categorías para categorizar al entrevistado, el entrevistador se presentó de una determinada manera ante el público lector y el entrevistado de turno.

Se procedió luego al cruzamiento de datos entre la cantidad de marcos presentes en una entrevista determinada y el tipo de fórmula de tratamiento pronominal empleado por los hablantes (Capítulo 6). Nuestro interés era determinar si existía una cierta relación entre el mayor o menor número de marcos de humor presentes en una entrevista, de acuerdo al uso de usted (indicador de +distancia -familiaridad) o al uso del vos (indicador de-distancia +familiaridad). Los resultados obtenidos no fueron concluyentes, ya que un bajo número de cambio de marcos sólo coincidió con el uso de usted en dos instancias. Por lo tanto, en futuras investigaciones, que incluyan corpora más extensos, será necesario someter a prueba esta idea.

Pudimos establecer, sin embargo, que en aquellos casos en los cuales el número de cambio de marcos fue mayor, el entrevistado logró un mayor despliegue de su identidad discursiva, y por el contrario, en aquellos en los que el número de marcos de humor fue menor, la identidad del entrevistador, encarnada en el personaje gracioso e ingenioso que habitualmente pone en escena, se hizo escasamente visible. Sin embargo, en nuestro corpus esto no 
estuvo en relación directa con el empleo de una determinada fórmula de tratamiento por parte de los interlocutores.

Hemos detallado los resultados obtenidos en esta investigación. Resta ofrecer algunas consideraciones finales.

Los estudios sobre la construcción de la identidad en el discurso dentro de la Etnometodología han sido numerosos. Especialmente a partir de los lineamientos establecidos por Sacks, el interés por los procesos de categorización asociados a la construcción de la identidad discursiva fue en aumento. Sin embargo, con posterioridad, muchos etnometodólogos se volcaron al análisis de las categorías secuenciales, que corresponde a una línea de investigación diferente, en detrimento del estudio de los procesos de categorización.

Nuestro interés en la manifestación de la identidad discursiva en la interacción nos llevo a reivindicar el estudio de los procesos de categorización como uno de las herramientas para dar cuenta de la constitución de la identidad de los participantes en la entrevista periodística de humor, en la cual los roles y actividades de los hablantes están constreñidos por el contexto en el que interactuan.

En este trabajo presentamos nuestro análisis particular de los recursos empleados por los hablantes durante la interacción con el propósito de construir su identidad discursiva. Este análisis ha producido algunos resultados de interés. Por un lado, surgieron como relevantes los procesos de auto y heterocategorización que posibilitaron la construcción de la identidad discursiva de cada entrevistado. Por otro lado, la noción de alternancia de marcos y la teoría de la performance nos permitieron explicar la forma en que el entrevistador construye su identidad en el discurso, conjuntamente con el empleo de una serie de recursos retóricos, discursivos y lingüísticos que generan humor y resaltan la habilidad creativa del performer. 
La construcción de la identidad de cada participante no se ha revelado cómo un proceso estático aislado o encapsulado en sí mismo, sino que, por el contrario, se ha manifestado cómo un fenómeno dinámico que se va entretejiendo en la urdimbre del discurso y se despliega en el aquí y ahora de la interacción, y que necesita del trabajo de sus participantes para ser llevado hacia adelante. En todo momento a lo largo de la investigación hemos destacado el carácter interactivo de la construcción de la identidad discursiva, sin el cual no es posible explicar cómo el accionar de cada participante influye sobre la producción discursiva del otro y contribuye a moldearla.

A través de este trabajo hemos intentado contribuir a explicar una mínima parte de los fenómenos que se manifiestan en la lengua en uso y que son de interés para la Etnometodología, la Pragmática, el Análisis del Discurso y el Análisis Conversacional, entre otros. Esta investigación nos ha permitido realizar un análisis coherente y echar luz sobre la manera en que los participantes de la interacción constituyen su identidad empleando diferentes recursos a su disposición. Restan por realizarse futuras investigaciones, en otros contextos y con corpora más extensos, que permitan determinar si algunos de los recursos que se han revelado cómo salientes en esta investigación pudieran ser representativos de la manera en que los hablantes realizan su trabajo identitario en otros contextos. 


\section{BIBLIOGRAFÍA}

ACADEMIA ARgentinA DE LeTRAs (2003) Diccionario del habla de los Argentinos. Buenos Aires, Espasa.

ADAM, J.M.(1991) Les textes: types e prototypes. Récit, description, argumentation, explication et dialogue. Série Linguistique, Paris, Nathan.

Albadalejo, T. (1991) Retórica. Madrid, Síntesis

Amossy, R. y A. Herschberg Pierrot. (2001) Estereotipos y clichés. Buenos Aires, Eudeba.

ANTAKI C. \& S. WIDDICOMBE (editors) (1998) Identities in Talk. London, Sage.

ANTAKI, C. \& S. WIDDICOMBE (1998a ) Identity as an Achievement and as a Tool. En: Antaki C. \& S. Widdicombe (editors) (1998) Identities in Talk. London, Sage.

ANTAKI, C.(1998) Identity Adscriptions in their Time and Place: "Fagin" and "The Terminally Dim”. En: Antaki C.\& S. Widdicombe (editors) (1998) Identities in Talk. London, Sage.

ARFUCH, L. (1995) La entrevista, una invención dialógica. Barcelona, Paidós

AUER, P. (1992) Introduction: John Gumperz' Approach to Contextualization. En: Auer, P. \& A. di Luzio. (eds.) The Contextualization of Language, Amsterdam, John Benjamins.

AustiN, J. L. (1996) Como hacer cosas con palabras ( 1962). Barcelona, Paidós Studio. (Traducción de Genaro Carrió y Eduardo Rabossi)

BAJTIN, M. (1998) Estética de la creación verbal. México, Siglo XXI.

BARTHES, R. (1966) L'ancienne rhétorique. Aide-mémoire, Communications, 16, pág. 172229

BATESON,G. (1972) Steps to an Ecology of Mind. New York, Ballantine

Bauman, R (1977) Verbal Art as Performance. Prospect Heights IL, Waveland Press, Inc.

Bauman, R. \& CH. BRIggs (1990) Poetics and Performance as Critical Perspectives on Language and Social Life. Annual Reviews Anthropology, 19 p.59-88.

Bauman, R. (2000) Language, Identity, Performance. En: Pragmatics, Vol. 10, № 1, March 2000. Edited by IprA, Antwerp, Belgium.

BAUMAN, R. (2001) El arte verbal como ejecución (1975). Traducción de Claudia Oxman. En Golluscio L. (comp.) (2001) Etnografía del habla. Textos fundacionales. Buenos Aires, Eudeba.

Bolívar, A. (1999) La construcción discursiva de los estereotipos sobre la identidad cultural. Ponencia de congreso presentada en XI Jornadas Lingüísticas de la ALFAL, Maracay, 1618 noviembre 1999.

BRown,R. \& A.GILMAN (1968) The Pronouns of Power and Solidarity, Joshua Fishman (ed.)Readings in the Sociology of Language, Le Hague-Paris-New York, Mouton Publishers. 
Calsamiglia, H. y A. Tusón Valls (1999) Las cosas del decir. Barcelona, Ariel.

CAMERON, D. (1999) Performing Gender Identity: Young Men's Talk and the Construction of Heterosexual Masculinity. En: The Discourse Reader, edited by Jaworsky and Coupland, Routledge, London.

CARRICABURO, N. (1997) Las fórmulas de tratamiento en el español actual. Madrid, Arcolibros.

Ciapuscio, G. E. (1994) Tipos textuales. Buenos Aires, UBA.

CIAPUSCIO, G. E. (2003) Formulation and Reformulation Procedures in Verbal Interactions between Experts and (Semi-) Laypersons. Discourse Studies, Volume 5 (2):207-233. London, Sage Publications.

Ciapuscio, G. E. Y W. KesselHeIM (1997) “Usted ¿qué es?” Categorizaciones y contexto institucional, en K. Zimmerman (ed.) Lenguaje y comunicación intercultural en el mundo hispánico, Frankfurt / M Vervuert, p.p 105-131.

CiAPuscio, G. E. E I. Kuguel (2002) Hacia una tipología del discurso especializado: aspectos teóricos y aplicados. En: Texto, terminología y traducción (2002) J. García Palacios y M.T. Fuentes Morán (Eds.) Salamanca, Almar.

Clayman, S. \& J. HeRitAge (2002) The News Interview. Studies in Interactional Sociolinguistics 16. Cambridge, C.U.P.

CLIFT, R. (1999) Irony in Conversation. En: Language in Society 28:4 , p. p. 523-553. U.S.A, C.U.P.

DAY, D. (1998) Being Ascribed and Resisting Membership of an Ethnic Group. En: Antaki C. and S. Widdicombe (editors) (1998) Identities in Talk. London, Sage.

DUCROT, O Y T.TODOROV (2003) Diccionario enciclopédico de las ciencias del lenguaje. Buenos Aires, Siglo XXI Editores. (Traducción de Enrique Pezzoni)

DURANTI, A. \& CH. GoOdWIN (editors) (1992) Rethinking Context. Cambridge, C.U.P

EDWARDS, D. (1991) Categories are for Talking. En: Theory and Psychology, Sage Vol. 4 $515-542$

EDWARDS, D (1998) The Relevant Thing about her: Social Identity Categories in Use. En: Antaki Ch, and S. Widdicombe (editors) (1998) Identities in Talk. London, Sage.

FItZgerald, R. \& W. Housley (2002) Identity Categorization and Sequential Organization: the Sequential and Categorial Flow of Identity in a Radio Phone-in. En: Discourse and Society, V. $13 \mathrm{~N}^{\circ}$ 5, September 2002.

GARCíA BARRIENTOS, J. L (1998) Las figuras retóricas. El lenguaje literario 2. Madrid, Arcolibros.

GARFINKEL,H. (1967) Studies in Ethnomethodology. Englewood Cliffs, NJ, Prentice Hall.

GILES,H., Coupland, J \& N. Coupland (EDS.) (1991) Contexts of Accommodation. Cambridge, C.U.P.

GoffMAN, E.(1974) Frame Analysis. New York, Harper and Row.

Goodwin,CH. \& M. GoodWIN (1992) Context, Activity and Participation. En:The Contextualization of Language. John Benjamin Publishings. Co Philadelphia. 
GRICE, H.P. (1975) Logic and Conversation. En: (eds.) P.Cole \& J. Morgan. Syntax and Semantics 3: Speech Acts. New York, Academic Press.

GÜLICH, E. (1986) Textsorten in der Kommunikationspraxis. En W.Kallmeyer (ed.)Handlungsmuster, Textsorten,Situationstypen. Düsseldorf, Schwann.

GüLICH, E. \& T. KOTSCHI (1995) Discourse Production in Oral Communication. Aspects of Oral Communication. U. Quastoff, Berlin / New York, de Gruyter.

GüLICH, E. (2003) Conversational Techniques Used in Transferring Knowledge between Medical Experts and Non-experts. Discourse Studies, vol. 5, Number 235-263. London, Sage Publications

GUMPERZ, J. (1982) Discourse Strategies. Cambridge. Cambridge University Press.

HAusendoRF, H. \& W. KesselHeIM (2002) The Communicative Construction of Group Relationships. A Basic Mechanism of Social Categorization. En: Us and Others. Social Identities across Languages, Discourses and Cultures. Ed. by Anna Duszak.

HeinemanN, W. \& D. VieHWEger (1991) Textlinguistik: eine Einführung. Tübingen, Niemeyer.

Heinemann, W. (2000) Clases textuales. Para la discusión sobre las clases textualesde base del comunicar. Retrospectiva y panorama. En: Textsorten. Reflexionen und Analyse, K. Adamzik (ed.) Tübingen, Stauffenburg. (Traducción informal de G.Ciapuscio)

HESTER, S. (1994) Les catégories en contexte. En L'enquête sur les catégories, Paris, Editions de L'Ecole des Hautes Études en Sciences Sociales, p. 219-242 (Raisons pratiques 5)

Hester, S. \& P. EgLIN (editors) (1997) Culture in Action. Studies in Membership Categorization Analysis, Lanham, MD, University Press of America.

HousLeY, W. \& R. FitzGERALD (2002) The Reconsidered Model of Membership Categorization Analysis. En Qualitative Research vol. 2 (1) 59-83. London, Sage Publications.

HOUSLEY, W. (2002) Moral Discrepancy and "Fudging the issue" in a Radio News Interview. BSA Publications Ltd., volume 36 (I) 5-21, London, Sage Publications.

HOUSLEY, W. (2003) Interaction in Multidisciplinary Teams. Cardiff Papers in Qualitative Research. Cardiff University. England, Ashgate.

JAfFe, A.( 2000) Comic Performance and the Articulation of Hybrid Identity. En: Pragmatics, Vol. 10, № 1, March 2000. Edited by IprA, Antwerp, Belgium.

JAYYUSI, L.(1984) Categorization and the Moral Order. London. Routledge \& Kegan Paul.

KESSELHEIM, W (1998), "Hay que distinguir". El discurso sobre la inmigración actual en la Argentina. En: Signo y Seña No 10, diciembre de 1998.

KeSSELHEIM, W (2003) Prozesse der Gruppenkonstitution: Die konversationelle Herstellung von Gruppen im aktuellen argentinischen Einwanderungsdiskurs [Procesos de constitución de grupos: la constitución conversacional de grupos en el discurso argentino actual sobre la inmigración] Tesis doctoral, Universidad de Bielefeld, Alemania.

KESSELHEIM, W (en prensa) La construcción y destrucción de límites entre grupos étnicos en la interacción. Universidad de Bayreuth. 
LEECH, G. (1977) Semántica. Madrid, Alianza Editorial.

LEVINSON, S. (1983) Pragmatics. Cambridge, C.U.P

MAtOEsIAN, G. (1999) The grammaticalization of Participant Roles in the Constitution of Expert Identity, Language in Society 28: 4 p. p. 491-521. U.S.A, C.U.P

MC CARTHY,M .\& R. CARTER (2004) “There's millions of them": hyperbole in everyday conversation. En: Journal of Pragmatics Vol.36 Issue 2 p.p 149-184, Feb.2004.

Mc ILVEnNy, P. (1996) Popular Public Discourse at Speaker's Corner: Negotiating Cultural Identities in Interaction. En: Discourse and Society Vol.7 Nº1, Jan.96, London, Sage.

MEY, J. (1993) Pragmatics. An Introduction. Oxford, Blackwell.

MORNER, K. \& R. RAUSCH (1998) NTC's Dictionary of Literary Terms. Chicago, NTC Publishing Group.

OXMAN, C. (1998) La entrevista de investigación en Ciencias Sociales. Buenos Aires, Eudeba.

QUIN, R.,(1995) Enfoques sobre el estudio de los medios de comunicación: la representación de estereotipos. En : Roberto Aparici (coord.) Educación Audiovisual. Buenos Aires, Ediciones Novedades Educativas. p. 37-50.

SACKS,H, (1992) Lectures on Conversation [1964-1972] Jefferson, Gail. (comp.), Cambridge, Mass, Blackwell.

SCHENKEIN, J. (1978) Identity Negotiations in Conversation,. En Schenkein, J. (ed.), Studies in the Organization of Conversational Interaction, New York, Academic Press, 57-78.

SCHIFFRIN, D., (1993) "Speaking for Another" in Sociolinguistic Interviews: Alignments, Identities and Frames. En: Tannen, D.(ed.) (1993) Framing in Discourse.New York, O.U.P.

SEARLE, J. R. (1986) Actos de habla. Madrid, Ediciones Cátedra, (Traducción de Luis Valdés Villanueva)

StRAeHLE, C.(1993) "Samuel?" "Yes, dear?" Teasing and Conversational Rapport. En: Tannen, D. (ed.) (1993) Framing in Discourse. New York, O.U.P

TANNEN, D. \& C. WALLAT, (1993) Interactive Frames and Knowledge Schemas in Interaction: Examples from a Medical Examination / Interview. En: Tannen, D.(ed.) (1993) Framing in Discourse. New York, O.U.P.

TANNEN, D. (ed.) (1993) Framing in Discourse. New York, O.U.P.

VAN DIJK, T. (2000) Ideología. Barcelona, Gedisa.

VAN DIJK, T. (compilador) (2000) El Discurso como Interacción Social. Barcelona, Gedisa.

WIDDICOMBE, S. (1998)“But you Don't Class Yourself”: the Interactional Management of Category Membership and Non-membership. En: Antaki C. \& S. Widdicombe (editors) (1998) Identities in Talk. London, Sage.

ZIMmeRMAN, D.(1998) Identity, Context and Interaction. En: Antaki C. \& S. Widdicombe (editors) (1998) Identities in Talk. London, Sage. 
Tabla I

\section{Marcos de humor}

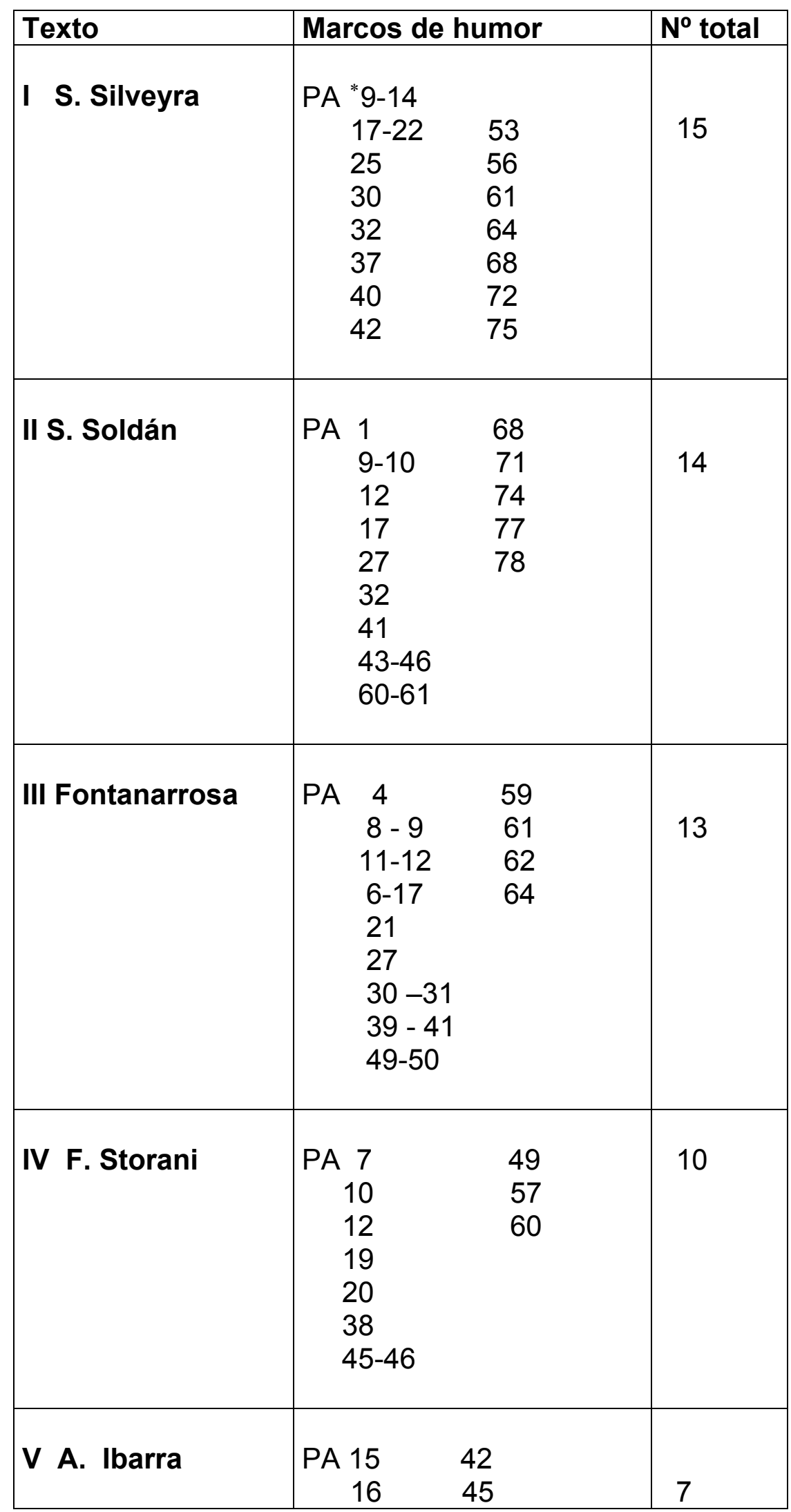

* Par adyacente 


\begin{tabular}{|c|c|c|c|}
\hline & $\begin{array}{l}19 \\
41\end{array}$ & $50-51$ & \\
\hline VI D. Cavallo & \multicolumn{2}{|l|}{$\begin{array}{r}\text { PA } 6 \\
8 \\
13 \\
60 \\
73 \\
74 \\
76\end{array}$} & 7 \\
\hline VII J.Weich & $\begin{array}{c}\text { PA } 4 \\
5 \\
10 \\
16 \\
22 \\
25 \\
34 \\
39\end{array}$ & $\begin{array}{ll}0 & 76 \\
2 & 82 \\
5 & 89 \\
9 & \\
4 & \\
6 & \\
3 & \\
5 & \end{array}$ & 19 \\
\hline VIII J.M Serrat & $\begin{array}{c}\text { PA } 7 \\
8 \\
11 \\
19 \\
23 \\
25 \\
26 \\
28\end{array}$ & $\begin{array}{l}30-32 \\
46 \\
63 \\
69 \\
71\end{array}$ & 13 \\
\hline IX Aito de la Rúa & $\begin{array}{l}\text { PA } 4 \\
\quad 9-10 \\
17-18 \\
27 \\
38 \\
42-47 \\
51 \\
55 \\
63-65 \\
72 \\
74\end{array}$ & $\begin{array}{l}76 \\
78 \\
80-81 \\
84 \\
90-91 \\
93 \\
96 \\
97-99 \\
103-105 \\
110-114 \\
129-130\end{array}$ & 22 \\
\hline X Charly García & $\begin{array}{r}\text { PA } 3 \\
17 \\
38 \\
65 \\
71 \\
75\end{array}$ & 84 & 7 \\
\hline
\end{tabular}




\begin{tabular}{|c|c|c|c|}
\hline XI N. Aleandro & $\begin{array}{l}\text { PA } 5 \\
11 \\
15 \\
20 \\
24 \\
38-39 \\
42-44 \\
61-62 \\
64-66 \\
70 \\
73\end{array}$ & $\begin{array}{l}74-76 \\
84-85 \\
89 \\
91 \\
100 \\
103-104\end{array}$ & 17 \\
\hline XII R. Terragno & $\begin{array}{l}\text { PA } 5 \\
\quad 10-14 \\
16 \\
20 \\
22 \\
40-42 \\
46 \\
56-58 \\
63-64\end{array}$ & $\begin{array}{c}66 \\
67 \\
70 \\
82 \\
89 \\
90 \\
104\end{array}$ & 16 \\
\hline $\begin{array}{l}\text { XIII Macaya } \\
\text { Márquez }\end{array}$ & $\begin{array}{r}\text { PA } 14 \\
33 \\
37 \\
65 \\
68\end{array}$ & & 5 \\
\hline XIV Gato Dumas & $\begin{array}{c}\text { PA } 2-3 \\
21-24 \\
26 \\
32 \\
50 \\
55\end{array}$ & $\begin{array}{l}62 \\
63 \\
66 \\
86 \\
87\end{array}$ & 11 \\
\hline XV N. Repetto & $\begin{array}{r}\text { PA } 18 \\
29 \\
31 \\
42 \\
46 \\
49\end{array}$ & $\begin{array}{l}54 \\
72 \\
76 \\
84 \\
95\end{array}$ & 11 \\
\hline XVI R. Alfonsín & $\begin{aligned} & \text { PA } 5 \\
& 9-10 \\
& 12 \\
&\end{aligned}$ & $\begin{array}{l}67 \\
69 \\
73-74 \\
\end{array}$ & 15 \\
\hline
\end{tabular}




\begin{tabular}{|c|c|c|c|}
\hline & $\begin{array}{l}17 \\
22 \\
24 \\
30 \\
33 \\
48 \\
58-59\end{array}$ & $\begin{array}{l}77 \\
82\end{array}$ & \\
\hline XVII R. Puerta & $\begin{array}{c}\text { PA } 1 \\
6 \\
8 \\
13 \\
15 \\
20 \\
24 \\
26 \\
42\end{array}$ & $\begin{array}{l}44 \\
46-48 \\
52 \\
57-61 \\
64 \\
65 \\
83 \\
85-86 \\
88 \\
91-94 \\
101\end{array}$ & 20 \\
\hline XVIII H. Roggero & $\begin{array}{l}\text { PA } 3 \\
\quad 4 \\
6 \\
13-15 \\
24 \\
33 \\
35 \\
41-42 \\
56 \\
63-66\end{array}$ & $\begin{array}{l}82 \\
87 \\
96-98 \\
102 \\
112 \\
127\end{array}$ & 16 \\
\hline XIX Pampita & 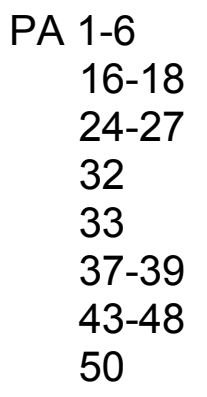 & $\begin{array}{l}59-62 \\
75 \\
83 \\
94 \\
95\end{array}$ & 13 \\
\hline XX Iván Noble & $\begin{array}{c}\text { PA } 2 \\
4 \\
12 \\
13 \\
16 \\
26 \\
32 \\
34-38 \\
\end{array}$ & $\begin{array}{l}44 \\
46 \\
48-51 \\
53-55 \\
68\end{array}$ & 13 \\
\hline
\end{tabular}




\begin{tabular}{|c|c|c|c|}
\hline XXI Florencia Peña & \begin{tabular}{|l} 
PA 4 \\
5 \\
10 \\
13 \\
$16-17$ \\
23 \\
32 \\
34 \\
35 \\
40
\end{tabular} & $\begin{array}{l}44 \\
48 \\
57 \\
59 \\
61 \\
71 \\
73 \\
89\end{array}$ & 18 \\
\hline XXII Angie Cepeda & $\begin{aligned} \text { PA } 2 \\
3 \\
5 \\
29 \\
31 \\
35 \\
51 \\
61\end{aligned}$ & & 8 \\
\hline XXIII P. Echarri & $\begin{array}{r}\text { PA } 10 \\
11 \\
12 \\
20 \\
24 \\
49 \\
53 \\
55 \\
57 \\
59\end{array}$ & & 10 \\
\hline XXIV A. Pichot & $\begin{array}{c}\text { PA } 2 \\
17 \\
28 \\
38 \\
41 \\
67-68 \\
72\end{array}$ & & 7 \\
\hline XXV Eloy Martínez & PA 3 & & 1 \\
\hline XXVI F. Luppi & $\begin{array}{r}\text { PA } 10 \\
14 \\
35 \\
40\end{array}$ & & 4 \\
\hline
\end{tabular}




\begin{tabular}{|c|c|c|c|}
\hline XXVII F.Arana & $\begin{array}{c}\text { PA } 1 \\
5 \\
15 \\
29 \\
42 \\
53 \\
54 \\
56\end{array}$ & & 8 \\
\hline $\begin{array}{l}\text { XXVIII J.L. } \\
\text { Rodríguez }\end{array}$ & $\begin{array}{c}\text { PA } 6 \\
10 \\
13 \\
17 \\
20-21 \\
24-25 \\
27 \\
30 \\
\end{array}$ & $\begin{array}{l}31 \\
48 \\
49\end{array}$ & 11 \\
\hline XXIX A. Cortez & $\begin{array}{r}\text { PA } 12 \\
13\end{array}$ & & 2 \\
\hline XXX J.A Badía & $\begin{array}{r}\text { PA } 3 \\
4 \\
5 \\
7 \\
21 \\
44\end{array}$ & & 6 \\
\hline XXXI L. Pereyra & $\begin{array}{c}\text { PA } 7 \\
8 \\
10 \\
12 \\
19-20 \\
30 \\
32 \\
48 \\
63\end{array}$ & & 9 \\
\hline XXXII A. Cormillot & $\begin{array}{r}\text { PA } 2 \\
7 \\
8 \\
39 \\
40\end{array}$ & $\begin{array}{c}45-46 \\
62-64 \\
71\end{array}$ & 8 \\
\hline XXXIII A. André & PA 4 & & \\
\hline
\end{tabular}




\begin{tabular}{|c|c|c|c|}
\hline & $\begin{array}{l}9 \\
13-14 \\
18 \\
21 \\
40 \\
43 \\
50-51 \\
52-53 \\
59 \\
65-66 \\
68\end{array}$ & & 12 \\
\hline XXXIV Nalbandian & $\begin{array}{l}\text { PA } 2 \\
\quad 3 \\
5 \\
23 \\
31-33 \\
35 \\
41 \\
66 \\
78-80 \\
83-84 / \\
86 \\
91-92\end{array}$ & & 12 \\
\hline XXXV F. Gianola & $\begin{array}{c}\text { PA } 3 \\
7 \\
9 \\
22 \\
24 \\
28 \\
29 \\
30 \\
33 \\
35-36\end{array}$ & $\begin{array}{l}44 \\
46 \\
57 \\
61\end{array}$ & 14 \\
\hline $\begin{array}{l}\text { XXXVI Hiena } \\
\text { Barrios }\end{array}$ & $\begin{array}{c}\text { PA } 1-6 \\
11 \\
49 \\
68 \\
72 \\
78 \\
81\end{array}$ & & 7 \\
\hline XXXVII G. Toscano & $\begin{array}{r}\text { PA } 5 \\
7\end{array}$ & $\begin{array}{l}47 \\
61\end{array}$ & 22 \\
\hline
\end{tabular}




\begin{tabular}{|c|c|c|c|c|}
\hline & $\begin{array}{l}14 \\
17 \\
21 \\
23 \\
29 \\
33 \\
34 \\
43 \\
44 \\
45\end{array}$ & & $\begin{array}{l}67 \\
70 \\
71 \\
73 \\
75 \\
79 \\
87 \\
88\end{array}$ & \\
\hline XXXVIII J. Bayly & $\begin{array}{cl}\text { PA } \\
3 \\
3 \\
4 \\
7 \\
9 \\
11 \\
12 \\
13 \\
15 \\
22 \\
23 \\
24\end{array}$ & $\begin{array}{l}26 \\
27 \\
32 \\
37 \\
43 \\
45 \\
46 \\
48 \\
49 \\
56 \\
64-65 \\
68 \\
70\end{array}$ & $\begin{array}{l}72 \\
73 \\
75 \\
80 \\
81 \\
86 \\
89\end{array}$ & 32 \\
\hline XXXIX M. Fabbiani & $\begin{array}{c}\text { PA } \\
2 \\
3 \\
8 \\
11 \\
16 \\
18 \\
20 \\
21 \\
22 \\
23\end{array}$ & $\begin{array}{l}24 \\
25 \\
29 \\
30 \\
31 \\
38 \\
39 \\
40 \\
44 \\
45 \\
50\end{array}$ & $\begin{array}{l}54 \\
56 \\
57 \\
65 \\
70\end{array}$ & 27 \\
\hline XL Bandana & $\begin{aligned} \text { PA } 1 \\
3 \\
5 \\
9 \\
19 \\
21 \\
22 \\
23 \\
25\end{aligned}$ & $\begin{array}{l}26 \\
39 \\
44 \\
51 \\
53\end{array}$ & & 14 \\
\hline
\end{tabular}


$\underline{\text { Tabla II }}$

\section{Formas pronominales de tratamiento}

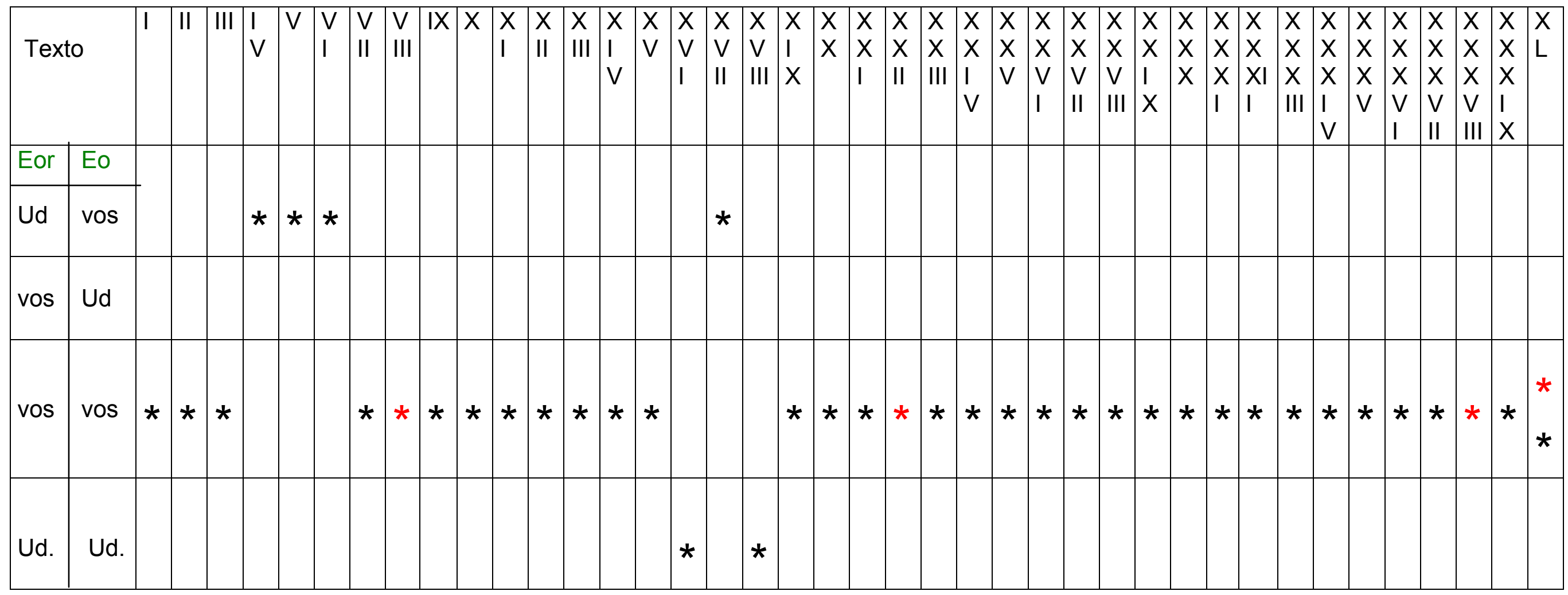

* vos / tu

Eo : Entrevistado

Eor: Entrevistador 
Tabla III

Recursos lingüísticos

\begin{tabular}{|c|c|c|c|c|}
\hline Texto & Entrevistado & Coloquial & Lunfardo & Vulgar \\
\hline I & Soledad Silveyra & $\begin{array}{l}\text { Jorobar } \\
\text { Ratón } \\
\text { Varonera } \\
\text { Tiraculpa }\end{array}$ & & \\
\hline II & Silvio Soldán & $\begin{array}{l}\text { Enganchar colifas } \\
\text { Mamero / papero } \\
\text { Pibes } \\
\text { Fachero }\end{array}$ & Minas & \\
\hline III & Fontanarrosa & $\begin{array}{l}\text { Mancar } \\
\text { Gasolero } \\
\text { Chupar (beber) } \\
\text { Picado (fútbol) }\end{array}$ & Laburo & \\
\hline IV & Federico Storani & Guardabosque (celoso) & & Dar bola \\
\hline $\mathrm{V}$ & Anibal Ibarra & $\begin{array}{l}\text { Tener arrastre } \\
\text { Hacer asco a } \\
\text { Levante } \\
\text { Seco (sin dinero) } \\
\text { Paqueta (elegante) }\end{array}$ & & \\
\hline VI & Domingo Cavallo & $\begin{array}{l}\text { Matarse (pelearse) } \\
\text { Pibe } \\
\text { Ratonearse } \\
\text { Pasarla bomba }\end{array}$ & & \\
\hline VII & Julián Weich & $\begin{array}{l}\text { Fachero } \\
\text { Piñas (golpes) } \\
\text { Viejo (padre) } \\
\text { Papero / mamero } \\
\text { Pibe } \\
\text { Levante } \\
\text { mufas }\end{array}$ & & \\
\hline VIII & Joan Manuel Serrat & Pibe & & \\
\hline
\end{tabular}




\begin{tabular}{|c|c|c|c|c|}
\hline & & Boliche & & \\
\hline IX & Aito de la Rúa & $\begin{array}{l}\text { Tiro al aire } \\
\text { Paquetas (elegantes) } \\
\text { Pibe } \\
\text { Reventar la plata } \\
\text { Viejo (Padre) } \\
\text { Revolear la chancleta } \\
\text { Ratonearse }\end{array}$ & $\begin{array}{l}\text { Atorrante } \\
\text { Bulín }\end{array}$ & \\
\hline $\mathrm{X}$ & Charly García & $\begin{array}{l}\text { Bicho raro } \\
\text { Plata (dinero) }\end{array}$ & & \\
\hline XI & Norma Aleandro & Viejos (padres) & Mishiadura & \\
\hline XII & Rodolfo Terragno & $\begin{array}{l}\text { Levante } \\
\text { Pibe } \\
\text { Piantavotos (del lunf. } \\
\text { Piantar) }\end{array}$ & & \\
\hline XIII & Macaya Márquez & $\begin{array}{l}\text { Pibe } \\
\text { Chupamedias }\end{array}$ & & \\
\hline XIV & Gato Dumas & $\begin{array}{l}\text { Piojo resucitado } \\
\text { Perejiles (tontos) } \\
\text { Paquete (elegante) } \\
\text { Curda }\end{array}$ & Mina & \\
\hline$X V$ & Nicolás Repetto & $\begin{array}{l}\text { Levante } \\
\text { Guacho }\end{array}$ & & \\
\hline XVI & Raul Alfonsín & $\begin{array}{l}\text { Gallego (español) } \\
\text { Pibe }\end{array}$ & & Dar bola \\
\hline XVII & Ramon Puerta & $\begin{array}{l}\text { Avivar } \\
\text { Timbero }\end{array}$ & & $\begin{array}{l}\text { Pendex } \\
\text { (vulgar } \\
\text { atenuado } \\
\text { de } \\
\text { "pendejo") } \\
\text { Joda } \\
\end{array}$ \\
\hline
\end{tabular}




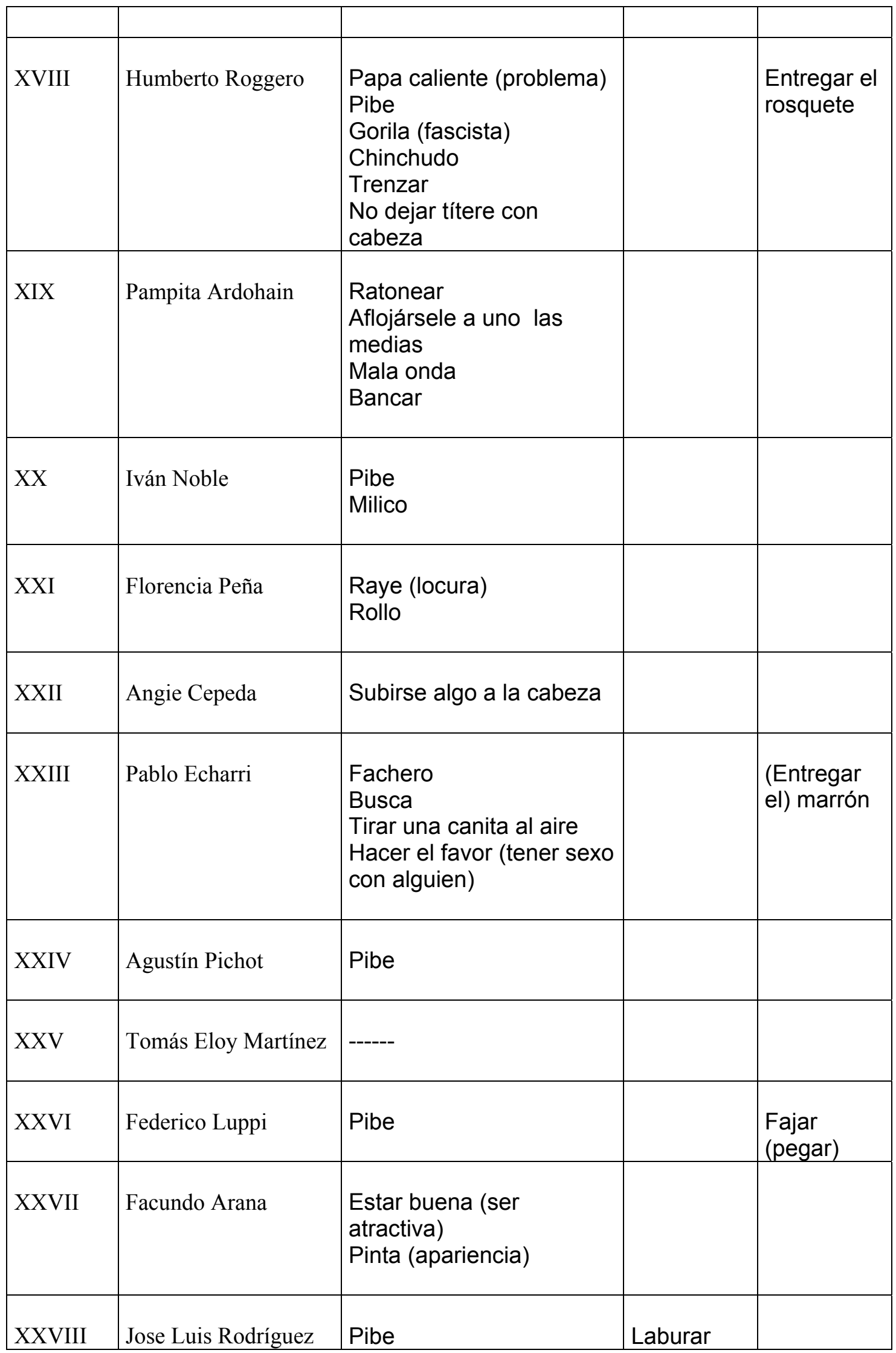




\begin{tabular}{|c|c|c|c|}
\hline XXIX & Alberto Cortez & --------- & \\
\hline XXX & Juan Alberto Badía & $\begin{array}{l}\text { Pibe } \\
\text { Gasolero } \\
\text { Pilcha }\end{array}$ & \\
\hline XXXI & Luciano Pereyra & $\begin{array}{l}\text { Viejos (padres) } \\
\text { Boliche }\end{array}$ & \\
\hline XXXII & Alberto Cormillot & $\begin{array}{l}\text { Pilchas } \\
\text { Curda }\end{array}$ & \\
\hline XXXIII & Arnaldo André & $\begin{array}{l}\text { Viejos (padres) } \\
\text { Lengualarga }\end{array}$ & Fajador \\
\hline XXXIV & David Nalbandian & $\begin{array}{l}\text { Pibe } \\
\text { Plata (dinero) } \\
\text { Escrache }\end{array}$ & \\
\hline XXXV & Fabián Gianola & $\begin{array}{l}\text { Pibe } \\
\text { Baboso } \\
\text { Mariconazo }\end{array}$ & Curro \\
\hline XXXVI & La Hiena Barrios & $\begin{array}{l}\text { Pibe } \\
\text { Pollerudo }\end{array}$ & \\
\hline XXXVII & Gabriela Toscano & $\begin{array}{l}\text { Importada (extranjera) } \\
\text { Ratonera } \\
\text { Revolear la chancleta }\end{array}$ & \\
\hline XXXVIII & Jaime Bayly & ----- & \\
\hline XXXIX & Mariana Fabbiani & $\begin{array}{l}\text { Agrandada } \\
\text { De pocas pulgas } \\
\text { Cole } \\
\text { Traga (estudiosa) } \\
\text { Lance }\end{array}$ & \\
\hline
\end{tabular}




\begin{tabular}{|l|l|l|l|l|}
\hline X L & Grupo Bandana & $\begin{array}{l}\text { Chinchuda } \\
\text { Paqueta }\end{array}$ & & \\
\hline
\end{tabular}

